\title{
Effect of Achieved Key Performance Indicators in Curriculum and Instruction on Internal Efficiency in Public Secondary Schools in Kisumu and Uasin Gishu Counties, Kenya
}

\author{
Ezekiel Nyangia ONYANGO ${ }^{1}$ John Aluko ORODHO ${ }^{* 2}$ and JohnNDERITU ${ }^{3}$ \\ 1. Doctor of Philosophy (PhD) graduate, School of Education, Department of Educational Management, Policy \\ and Curriculum Studies, Kenyatta University, Kenya Email: ezekieln64@gmail.com \\ 2. Associate Professor, Corresponding Author, and supervisor of Ezekiel Nyangia Onyango, School of \\ Education, Department of Educational Management, Policy and Curriculum Studies, Kenyatta University, \\ Kenya; Email: orodhojohn@gmail.com \\ 3. Lecturer, and Supervisor of Ezekiel Nyangia Onyango, Department of Educational Management, Policy and \\ Curriculum Studies, School of Education, Kenya
}

\begin{abstract}
The purpose of this study was to establish the effect of achieved key performance indicators in curriculum and instruction on internal efficiency regarding promotion and retention rates. The convergent parallel mixedmethods design was adopted in the study. A sample size of 342 consisting of 57 principals, 57 PA chairpersons; and 228 teachers for quantitative strand and a further 54 respondents consisting of 9 principals, 9 PA chairpersons and 36 teachers for qualitative strand. Questionnaires, interview schedule, document analysis and observation schedule were used to collect data. The study established that achieved key performance indicators in curriculum and instruction was moderate and had more influence on grade promotion rate than on retention rate hence moderate influence on internal efficiency. It was concluded that achieved key performance indicators has positive high influence on internal efficiency in public secondary schools. The study recommends that The Ministry of Education should increase resources for achievement of key performance indicators in curriculum and instruction.
\end{abstract}

Keywords: Achieved key performance indicators, curriculum and instruction, grade promotion rate, retention rate, Internal Efficiency, public secondary schools, Kenya.

DOI: $10.7176 /$ RHSS/12-4-03

Publication date: February $28^{\text {th }} 2022$

\section{INTRODUCTION AND CONTEXT}

\subsection{Background to the Problem}

Internal efficiency in regard to this study involves students' promotion and retention contrary to repetition and dropout. Students' promotion is the progression of students to the next grade at the beginning of a new academic year. It intensifies flow of students within the education cycle and it is an issue of school-based factors. According to study by Otieno (2015) on school- based determinants of promotion rates among public primary schools in Suba Sub -County, Kenya, it was established that pupil/ teacher ratio was a more prominent factor affecting promotion of pupils. The finding concurs with Adepoju \& Oluchukwu (2011) reporting that several state governments in Nigeria have struggled to make it a policy having not more than 30 students per class in public secondary schools as a way of improving the students' academic performance. This means that the teacher/ student ratio is maximized for effective curriculum delivery. The other factors which the literature identify as school-based factors which discourage good performance hence low progression are lack of supervision, monitoring and evaluation machinery and unavailability of good textbooks among other factors. A paradigm shift is required for these factors to be resolved through achievement of Key Performance Indicators outlined in school strategic plan.

Achievement of Key Performance Indicators is a result of well thought of strategies. A strategy concentrates on the future. According to Chemei, Leboo and Koech (2014), strategy is a disciplined effort to produce fundamental decisions and actions that shape and guide what an organization is, what it does and how it does it with a focus on the future. It is a specific purpose oriented plan. Kaufman (2000) avers that it is a means of achieving mission and the results outlined in goals. It is a means to an end, a way to get results. Strategies are the way roles are played. In this regard, strategies of implementation of strategic plan on key concepts refer to the way roles are played to ensure these concepts are turned into results in form of Key Performance Indicators. This concurs with an established fact that for an organisation to reach the envisioned state, it translates strategy into action via strategic objectives whose level of achievement is demonstrated by KPI Gupta (2015) . What was not known were the achieved KPIs under Curriculum and Instruction and their effect on internal efficiency in public secondary schools in Kisumu and Uasin Gishu Counties which the current study established.

Achieved KPI under curriculum and instruction as part of strategic plan implementation is expected to help 
schools improve their internal efficiency by addressing causes of such inefficiencies. This is because strategic planning came on the back of high inefficiencies and coincided with bad conditions of resources in schools (Itegi, 2016) which various studies relate to dropout and grade repetition rates (Adigwe, 1997; Mumina, 2013; Yusuf \& Sofoluwe, 2014). Issues of concern pointed out by Kisumu and Uasin Gishu Counties' QASOs affecting the students which coincided with the introduction of strategic planning process were majorly school based factors such as rigid students grade to grade promotion policies by schools fighting for better mean scores, lack of teaching and learning resources within schools due to insufficient government and public funding, among others. The concern was, what effect did achieved key performance indicators under curriculum and instruction have on internal efficiency?

\subsection{State of the Art Review}

A study by Macgowen (2007) was set to explore the impact of school teaching and learning resources on student achievement, attendance, behaviour, completion rate and teacher turnout rate at selected Texas High schools. When the school resources condition for the sampled schools was determined by the Total Learning Environment Assessment (TLEA) Information given by the principals or their representation in high school campuses in Texas with high enrolment and economically disadvantaged enrolments less than $40 \%$, the study established that there was no statistically significant relationship between the students achievement, attendance and completion rate measures and school facility conditions. This is contrary to Souck and Nji (2017) finding that school facilities affect internal efficiency. The gaps found here is inconsistency, that the information was got from only one source and the items are mixed up and not specific in relation to whether they are under curriculum and instruction or physical infrastructure. The current study diversified sources of information as well as methods of collecting them and investigated the effect of achieved key performance indicators specifically under curriculum and instruction to resolve the conflict.

The finding of Macgwen (2007) is exact contrast of the findings of the study by Charles (2009) undertaken on internal efficiency measures in promotion of access and completion rates in public secondary schools of Bungoma South District. The study established schools did not have adequate provision of teaching and learning resources which was a great hindrance in attainment of qualitative objective of education. These two empirical findings are divergent and can only be resolved through mixed method research. The current study found out the achieved Key Performance Indicators in curriculum and instruction and what the effect was on promotion rate in public secondary schools in Kisumu and Uasin Gishu Counties.

Strategic Planning as a management tool has been given acclamation internationally as an effective tool in improving the performance of not only state owned enterprises but also government departments (IIEP, 2010). It is a determination of an organization's success or failure. Chukwumah, et al. (2015) and IIEP (2010) concur that this makes strategic planning vital to any organizational work performance. Other literature also concur that strategic planning provides better performance of significance than unplanned, opportunistic adaptive approach (IIEP, 2010; Republic of South Africa, 2013). It presents an integrated model for other forms of planning. This requires matching the activities of the organization to its environment and also the organizations resource capabilities in order to realize the purpose of the organization (Khan, et al., 2014). The gap was how the schools implemented their strategies which the current study established.

The literature further confirms that strategic planning has been used in schools in developed countries leading to school improvement. IIEP (2010), equally posits that strategic plan implementation in schools in developed countries has led to school improvement hence internal efficiency. The literature emphasizes that in USA, strategic planning follows a four step process for planning a school wide programme, conducting a process, designing the school programme, implementing action plans, and evaluating the programme. Such process enables the schools to identify their key priority areas with specific components/ concepts to be fixed to realize the strategic goals. This is in tandem with Khan, et al. (2014) confirming that planning is a process of preparing ways to use resources more economically and efficiently in order to achieve the purpose of the company, which in this case, the purpose of the school.

In developing countries, schools development plan entails assessing their current state of the school development plan and providing information about it. This enables the schools to identify their strategic issues. According to Kaufman and Herman (2018), a strategic issue is one that must be resolved or fixed if an institution has to achieve its mission. An issue is strategic if it stands between the members of the school and achieving the school mission. The mission defines the kinds of things the school (institution) will do - the role to be played by the stakeholders as defined by the service they provide and for whom (Kaufman, et al., 2018). In a school set up, the following are the strategic issues or priority areas: staff/ personnel; students; curriculum and instruction; physical infrastructure and finance.

According to the literature, during school scanning through SWOT analysis the key concept/ component under each strategic issue is identified. The literature emphasizes that it is tempting for any institution to focus first on strategies and activities that are believed will get better results before deciding which results should be 
changed and why. The results to be changed are what are referred to as key concepts or components under strategic issue which must be fixed in order to achieve the desired goal given by Key Performance Indicators. A number of studies have identified what could be grouped as key concepts under each strategic issue as the problems responsible for low internal efficiency.

Regionally, in Nigeria for instance, secondary schools are characterized by problems, responsible for low internal efficiency such as dilapidated infrastructures, inadequate staffing, ill - motivated teachers, poor funding, lack of essential facilities, improper mission interpretation, inappropriate curricula, students unrest among others (Chukwumah,et al., 2015). Low internal efficiency is in form of wastage displayed by the repetition and drop out of students. The problems mentioned touch various priority areas but the current study sought to establish the effect achieved key performance indicators addressing problems specifically in curriculum and instruction on retention rate. This is further explained by a study by Sang, Koros and Bosire (2013) conducted on dropout levels of public secondary schools in Kericho District in relation to the selected characteristics.

The main objective of the study was to determine the dropout level in public secondary schools in Kericho district by the school characteristics for the years 2004-2007. The study established that school characteristics contributed to differences in dropout rates in schools and that dropout rates decreased with increasing levels of schooling. It also established that the general mean dropout rate in classes was higher in day schools compared to boarding schools except in form two. The mean dropout rate was higher in form two classes for both single sex and mixed schools though mixed schools generally recorded a higher mean dropout rate. The study recorded that most schools had not put in place measures to deal with dropout in form two which recorded the highest rate.

Due to foregoing reason, Reeves (2007) in Wanjala and Rarieya (2014) emphasizes that the purpose of strategic planning is to create competitive advantage. This would make schools more attractive to stay in than dropout to the external environment. On the other hand, other researchers argue that some schools' plans are not comprehensive since they focus on material resources for the school such as buses and buildings, ignoring teaching and learning (Reeves 2008; Rumelt, 2011). Such schools lay great emphasis on the results of paper and pencil tests, thereby ignoring the goal of developing an all-round student (Wanjala \& Rarieya, 2014). In addition, some strategic plans display ineffective programmes to establish, monitor and evaluate growth in teacher performance and professional development, when actually this area is crucial in improving classroom practice and teaching methodology, which finally improves student achievement (Baloglu, Karadag \& Karaman 2008 ; Wanjala \& Rarieya, 2014). The current study therefore sought to establish achieved key performance indicators aimed at developing an all-round student in curriculum and instruction and their effect on retention rates.

\subsection{Purpose and Objectives /Hypotheses}

The study sought to achieve the following objectives:

i) To establish the effect of achieved key performance indicators in curriculum and instruction on grade promotion rate in public secondary schools in Kisumu and Uasin Gishu Counties, Kenya.

ii) To investigate the effect of achieved key performance indicators in curriculum and instruction on retention rate in public secondary schools in Kisumu and Uasin Gishu Counties, Kenya.

\section{0 . RESEARCH DESIGN AND METHODOLOGY}

\subsection{Research Design}

The study employed convergent parallel mixed methods design which is one of the six variants of mixed methods of research designs (Cresswell, 2014). It mixes the results (triangulation) for supportive or nonsupportive findings (Creswell, 2014) by merging the two data bases in side-by-side comparison during overall interpretation shown in Figure 1.

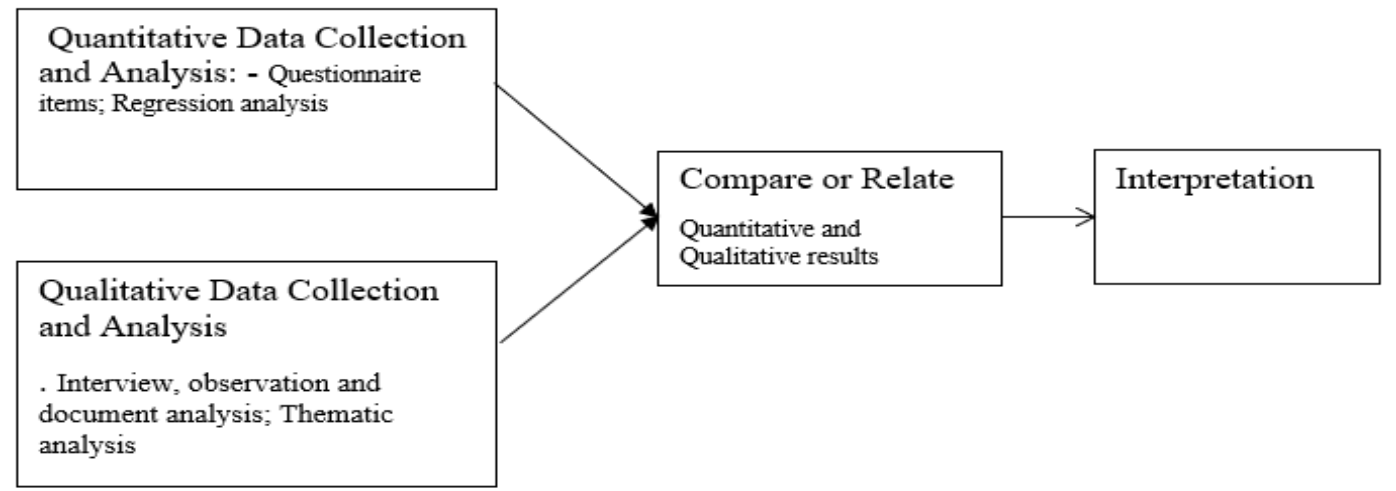

Figure 1: The convergent parallel design model

Source: (Creswell, 2014) 
This design was chosen for the current study because of inconsistent results of the previous studies on the relationship between strategic planning and organizational performance which had been too general and not specific on the aspect of performance; and which used only one method (Orodho, Nzabalirwa, Odundo, Waweru $\&$ Ndayambaje, 2016). The target population was 2226 consisting of 371 Principals (221 from Kisumu and 150 from Uasin Gishu Counties); 1484 class teachers (884 and 600 from Kisumu and Uasin Gishu Counties respectively) and 371 PA chairpersons (221 and 150 from Kisumu and Uasin Gishu Counties respectively).

\subsection{Population and Sample}

The sample size for quantitative data was 342 respondents (15.4\% of target population) consisting of 57 principals, 228 teachers and 57 PA chairpersons. Purposive sampling was used to select the principals and PA chairpersons while teachers were selected using simple random sampling. The sample size for qualitative data was 54(15.4\% of sample size for quantitative data) made up of 9 principals, 36 teachers and 9 PA chairpersons. All these respondents were purposively sampled. Four types of instruments: questionnaires, interview schedule, document analysis form and observation checklist. The questionnaires were used to obtain quantitative data from the principals, teachers and PA chairpersons while interview schedule was used to gather qualitative data from the principals, teachers and PA chairpersons who participated in qualitative strand of data collection. Document analysis form was used to ascertain enrolment records and clarity of the mission and vision statements. Finally, observation checklist was used to check the evidence of the awareness of vision and mission statements by the stakeholders (Orodho,2017).

\subsection{Data Analysis}

The quantitative data generated through questionnaires were edited and keyed in to a computer spreadsheet in standard format to facilitate computation of descriptive and inferential statistics using Statistical Package for Social Sciences (SPSS) version 20.0 .(Orodho, Ampofo, Bizimana \& Ndayambaje,2016). The descriptive statistics such as percentage and frequency distribution; and inferential statistics such as simple and stepwise multiple regressions were used to analyse the quantitative data. Qualitative data was analysed with the guidance of grounded theory under themes consistent with the research objectives; and conclusions made on the Basis of trends and patterns of responses.

\section{FINDINGS AND DISCUSSION}

\section{Achieved key Performance Indicators in Curriculum and Instruction and Internal Efficiency}

The main purpose of the study was to determine the effect of achieved key performance indicators in curriculum and instruction on internal efficiency in public secondary schools in Kisumu and Uasin Gishu Counties, Kenya. The addressed issues were as follows: The three prioritized subjects whose performances were being improved, the level of achievement of strategies of improving the performance in the chosen subject areas, the highest level of improvement of performance in the chosen subject areas in the last five years, the schools' participation in cocurricular activities, the highest level of participation in co- curricular activities reached and the effect of the achieved key performance indicators in curriculum and instruction on retention and grade promotion rates. The data were gathered using quantitative and qualitative methods concurrently.

\section{(i) Three Prioritized Subjects for Improved Performance}

Three prioritized subjects were considered in this study to mean the most poorly performed subjects targeted for performance improvement in the school. The study regarded this variable because it is the starting point when considering improvement of curriculum and instruction and therefore one of the key factors that could affect grade promotion rates and retention rates (Ricardo, et al., 2010). The principals, teachers and PA chairpersons were thus requested to indicate three subjects that the school had been working on to improve their performance during the strategic plan implementation period. They gave their responses per subject.

\section{(a) Subject 1 prioritized for improved performance}

Subject 1 prioritized for improved performance in this study refers to the subject which the school considered to be the worst performing subject at all levels and required to be given first priority for improvement. This variable could positively affect the students' performance leading to improved grade promotion and retention rates hence internal efficiency. Therefore, to determine the effect of achieved key performance indicators in curriculum and instruction on internal efficiency in the sampled public secondary schools, the principals, teachers and PA chairpersons were requested to indicate the subject given priority number 1 for improved performance by their schools. Their responses are presented in Figure 2 in form of percentages. 


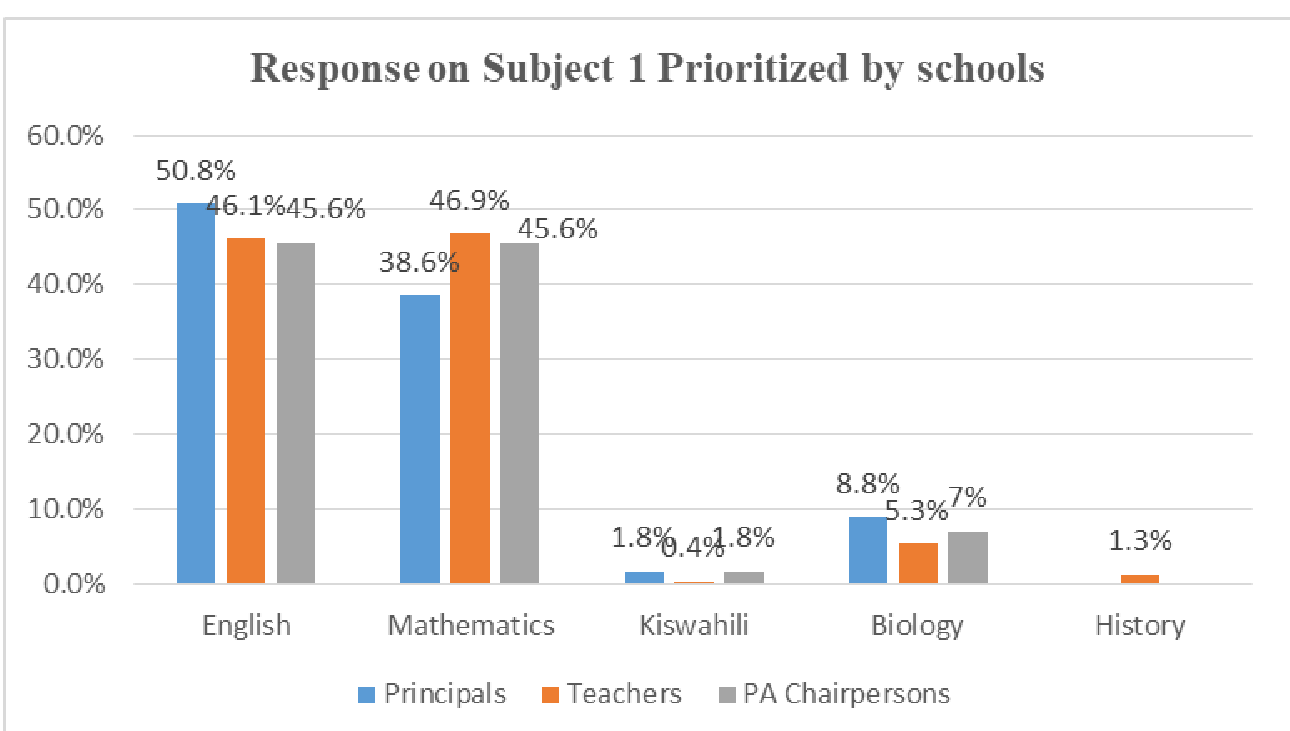

Figure 2: Responses of principals, teachers and PA chairpersons on subject 1 prioritized by schools

Source: Principals' questionnaire, teachers' questionnaire and PA chairpersons' questionnaire.

From Figure 2, majority (50.9\%) of the principals indicated English as subject 1 prioritized by the schools while only $46.1 \%$ of the teachers indicated the same subject. English and Mathematics were each indicated by equal number $(45.6 \%)$ of PA chairpersons as subjects 1 prioritized by the schools. On the other hand, $46.9 \%$ and $38.6 \%$ of teachers and principals respectively indicated Mathematics as subject 1 prioritized by schools. Another subject which was preferred by the respondents was Biology which was indicated by $8.8 \%, 7.0 \%$ and $5.3 \%$ of principals, PA chairpersons and teachers respectively while Kiswahili was indicated by $1.8 \%$ of principals and PA chairpersons each and $0.4 \%$ of teachers. Lastly, History was indicated by only $1.3 \%$ of teachers.

The finding implies that majority of the schools had most problem with the performance in both English and Mathematics. This could be because these are compulsory subjects whose performance affects students' career choice and yet sometimes they have a negative attitude towards the subject.

(b) Subject 2 prioritized for improved performance

Subject 2 prioritized for improved performance in this study refers to the subject which the school considered to be worse performing subject at all levels and required to be given second priority for improvement. This variable could positively affect the students' performance leading to improved grade promotion and retention rates hence internal efficiency. Therefore, to determine the effect of achieved key performance indicators in curriculum and instruction on internal efficiency in the sampled public secondary schools, the principals, teachers and PA chairpersons were requested to indicate the subject given priority number 2 for improved performance by their schools. Their responses are presented in Table 1.

From the Table 1, majority of the respondents (43.9\% of principals, $42.1 \%$ of the PA chairpersons and $39.9 \%$ ) indicated Maths as subject 2 prioritized by the schools. Another preferred subject was Biology which was indicated by $31.1 \%, 28.1 \%$ and $26.3 \%$ of teachers, principals and PA chairpersons respectively. Another subject worth reporting is Chemistry which was indicated by same number $(15.8 \%)$ of both principals and PA chairpersons as subject 2 prioritized by the schools. Kiswahili was also indicated by $12.3 \%, 10.1 \%$ and $1.8 \%$ of PA chairpersons, teachers and principals respectively while History, CRE, Physics, Geography and Agriculture were indicated by very minimal percentage of principals, teachers and PA chairpersons. 
Table 1: Responses of principals, teachers and PA chairpersons on subject 2 prioritized by schools

\begin{tabular}{|c|c|c|c|c|c|c|}
\hline \multirow[t]{2}{*}{ Subject } & \multicolumn{2}{|c|}{ Principal } & \multicolumn{2}{|c|}{ Teachers } & \multicolumn{2}{|c|}{ PA Chairperson } \\
\hline & $\mathbf{N}_{1}$ & $\%$ & $\mathbf{N}_{2}$ & $\%$ & $\mathbf{N}_{3}$ & $\%$ \\
\hline English & 1 & 1.8 & 3 & 1.3 & & \\
\hline Maths & 25 & 43.8 & 91 & 39.9 & 24 & 42.1 \\
\hline Kiswahili & 1 & 1.8 & 23 & 10.1 & 7 & 12.2 \\
\hline Biology & 16 & 28.0 & 71 & 31.1 & 15 & 26.3 \\
\hline Chemistry & 9 & 15.8 & 32 & 14.0 & 9 & 15.8 \\
\hline History & 4 & 7.0 & 3 & 1.3 & 1 & 1.8 \\
\hline CRE & 1 & 1.8 & & & 1 & 1.8 \\
\hline Physics & & & 1 & 0.4 & & \\
\hline Geography & & & 3 & 1.3 & & \\
\hline Agriculture & & & 1 & 0.4 & & \\
\hline Total & 57 & 100 & 228 & 100 & 57 & 100 \\
\hline
\end{tabular}

Source: Principals' questionnaire, Teachers' questionnaire and PA chairpersons' questionnaire

$\mathrm{N}_{1} \quad=57$

$\mathrm{N}_{2} \quad=228$

$\mathrm{N}_{3} \quad=57$

The finding reveals that majority of the schools preferred Mathematics and Biology as second prioritized subjects for improvement. This presents Mathematics as a popular subject for improvement because majority of the schools had considered it for priority number 1 and again it was considered for priority number 2 by majority of the schools.

\section{(c) Subject 3 prioritized for improved performance}

Subject 3 prioritized for improved performance in this study refers to the subject which the school considered to be bad performing at all levels and required to be given second priority for improvement. This variable could positively affect the students' performance leading to improved grade promotion and retention rates hence internal efficiency. Therefore, to determine the effect of achieved key performance indicators in curriculum and Instruction on internal efficiency in sampled public secondary schools, the principals, teachers and PA chairpersons were requested to indicate the subject given priority number 3 for improved performance by their schools. Their responses are presented in Table 2.

Table 2: Responses of principals', teachers' and PA chairpersons' on Subject 3 chosen to be improved by schools

\begin{tabular}{|c|c|c|c|c|c|c|}
\hline \multirow[t]{2}{*}{ Subject } & \multicolumn{2}{|c|}{ Principals } & \multicolumn{2}{|c|}{ Teachers } & \multicolumn{2}{|c|}{ PA Chairpersons } \\
\hline & $\mathbf{N}_{1}$ & $\%$ & $\mathbf{N}_{2}$ & $\%$ & $\mathbf{N}_{3}$ & $\%$ \\
\hline English & 2 & 3.5 & 3 & 1.3 & & \\
\hline Maths & 1 & 1.8 & & & & \\
\hline Kiswahili & 8 & 14.0 & 26 & 11.4 & 9 & 15.8 \\
\hline Biology & 4 & 7.0 & 23 & 10.1 & 7 & 12.3 \\
\hline Chemistry & 24 & 42.1 & 115 & 50.4 & 28 & 49.1 \\
\hline Physics & 6 & 10.5 & 33 & 14.5 & 9 & 15.8 \\
\hline History & 1 & 1.8 & 2 & 0.9 & 1 & 1.8 \\
\hline Geography & 4 & 7.0 & 6 & 2.6 & 1 & 1.8 \\
\hline CRE & 2 & 3.5 & 7 & 3.1 & & \\
\hline Agriculture & 1 & 1.8 & 7 & 3.1 & 1 & 1.8 \\
\hline Business Studies & 3 & 5.3 & 5 & 2.2 & & \\
\hline Computer Studies & 1 & 1.8 & 1 & 0.4 & 1 & 1.8 \\
\hline Total & 342 & 100 & 342 & 100 & 342 & 100 \\
\hline
\end{tabular}

Source: Principals' questionnaire, Teachers' questionnaire and PA chairpersons'

$\mathrm{N}_{1} \quad=57$ questionnaire

$\mathrm{N}_{2} \quad=228$

From Table 2, majority of respondents $(50.4 \%$ of teachers, $49.1 \%$ of PA chairpersons and $42.1 \%$ of principals) indicated that schools selected Chemistry as their subject 3 to be improved. This was followed by Physics at a very wide range of being selected by only $15.8 \%, 14.5 \%$ and $10.5 \%$ of PA chairpersons, teachers 
and principals respectively while $15.8 \%$ of PA chairpersons, $14 \%$ of principals and $11.4 \%$ of teachers selected Kiswahili and the least number (less than $2 \%$ of the categories of respondents) selected Computer Studies.

The finding reveals that the most preferred subject by schools as Subject 3 was Chemistry. The results from

Figure 2 and Tables 1 and 2, therefore reveal that most schools selected either English or Mathematics as Subject 1, either Maths or Biology as Subject 2 and Chemistry as Subject 3. The findings are in tandem with STEM requirement.

The qualitative findings also reveal that most sampled schools in the study locale prioritized Mathematics, Chemistry and Biology in that order. This is confirmed by a number of respondents who were interviewed and gave very insightful information on this issue. One of the teachers highlighted that:

We have Mathematics, Chemistry then Biology. Chemistry is compulsory. We have been working on Mathematics, Chemistry and Biology because students have not been doing well in them for the past years (T2).

From the PA chairpersons, one of them had this to say concerning the selected subjects:

In the recent past, the performance of Chemistry has not been good, Biology and Mathematics (PA6).

The principals added their voices to corroborate what the other respondents had given and one of them had this to say:

We have been concerned about sciences, because of the government policy is on the same. As a school we decided to put more effort on Chemistry, Mathematics and Biology but working with Chemistry most (P8).

From the foregoing, the dominant tone in terms of subject selections is mostly about Mathematics and sciences, more particularly Chemistry, Biology and Physics. Other schools are also concerned about Languages. It is also evident that subjects' selection is influenced either by past poor performance or by Government policy.

The results from both quantitative and qualitative findings concur that Mathematics and Science subjects, especially Chemistry and Biology need improvement of performance. This targeting has perhaps been influenced by either past poor performance or Government policy in relation to Science Technology Engineering Mathematics (STEM).

According to Rajput (2019), STEM is having critical position at the centre of Kenya's ability to attain Vision 2030. However, Kenya, like any other African countries, faces immense challenge in the field of STEM at all levels of education including secondary, in terms of performance, enrolment and gender disparity. This concurs with the findings about the performance, in the last five years, of the targeted subjects for improvement which was reported by the majority of the respondents to be fluctuating but with improvement as can be seen in the next section of this report.

\section{(ii) Highest Subject Performance Improvement from 2014 to 2018}

Highest subject performance improvement from 2014 to 2018 was considered in this study to mean highest performance improvement for subjects which were prioritized in Figure 2 and Tables 1 and 2. The period between 2014 and 2018 was chosen because it falls within the period when most of the sampled schools started the implementation of their strategic plans. This information is significant because it was influenced by the level of achievement of Key Performance Indicators in Curriculum and Instruction hence effect on grade promotion and retention rates. The principals, teachers and PA chairpersons were requested to indicate the performance of the selected subjects to help the researcher in working out the highest performance improvement level from 2014 to 2018. The results based on the responses were as presented in Figures 3, 4 and 5.

\section{(a) Highest Subject 1 Performance Improvement from 2014 to 2018}

Highest subject 1 performance improvement from 2014 to 2018 refers to highest performance in the subjects which sampled schools had given priority number 1 for improvement during the indicated period. Majority had prioritized English and Mathematics while others had indicated Kiswahili and other subjects as found in Figure 2. This information is important because improvement in these subjects would be an indication that the students were positively benefiting and that would improve grade promotion and retention rates hence, internal efficiency which was an independent variable for the study. The principals, teachers and PA chairpersons were therefore requested to indicate the performance of the selected subject 1 to help the researcher in working out the highest performance improvement level from 2014 to 2018. The results based on the responses are as presented in Figure 3. 


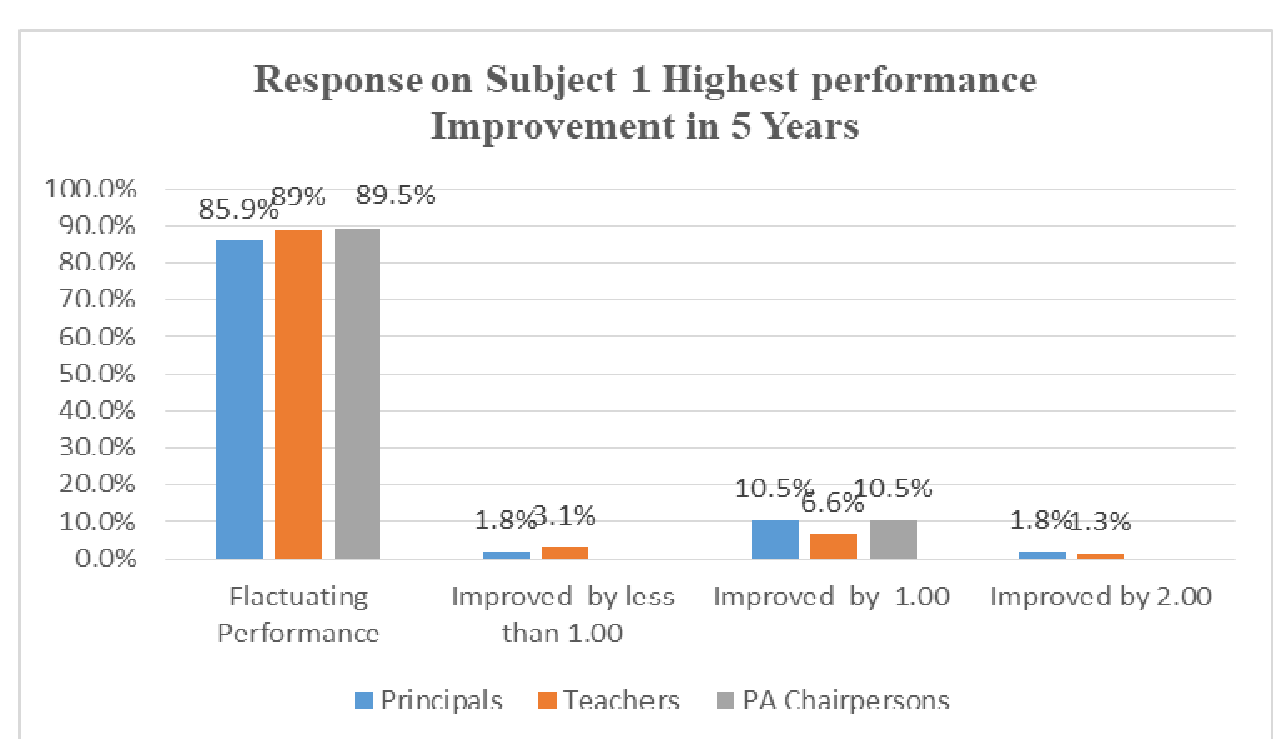

Figure 3: Principals', teachers' and PA chairpersons' response on subject 1 highest performance improvement

Source: Principals' questionnaire, teachers' questionnaire and PA chairpersons' questionnaire

From Figure 3, majority of the respondents $(89.5 \%$ of the PA chairpersons, $89 \%$ of teachers and $85.9 \%$ of principals) indicated that the performance between 2014 and 2018 of prioritized subject 1 had been fluctuating while $10.5 \%$ of both principals and PA chairpersons and $6.6 \%$ of teachers noted improvement by mean of 1.00 . Finally, improvements by mean of less than 1.00 and more than 2.00 were indicated by $1.8 \%$ of principals for both; and $3.1 \%$ and $1.3 \%$ of teachers respectively. The finding reveals that majority of the schools had their performance in subjects prioritized number 1 for improvement fluctuating but with improvement. This implies that strategies for improvement required a bit of time to be implemented.

\section{(b) Highest Subject 2 Performance Improvement from 2014 to 2018}

Highest subject 2 performance improvement from 2014 to 2018 refers to highest performance in the subjects which sampled schools had given priority number 2 for improvement during the indicated period. Majority had prioritized Mathematics and Chemistry while others had indicated Biology and other subjects as found in Table 1. This information is important because improvement in these subjects would be an indication that the students were positively benefiting and that would improve grade promotion and retention rates hence internal efficiency which was an independent variable for the study. The principals, teachers and PA chairpersons were as such requested to indicate the performance of the selected subject 2 to help the researcher in working out the highest performance improvement level from 2014 to 2018. The results based on the responses were as presented in Figure 4.

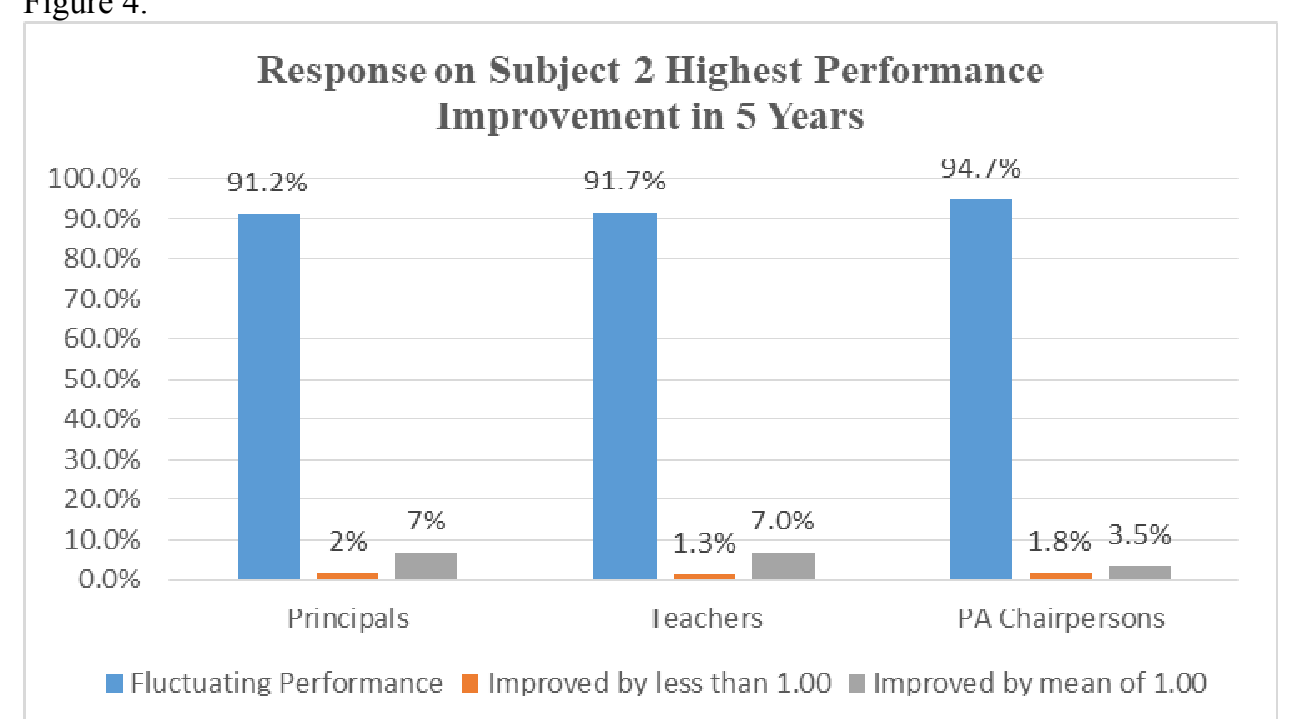

Figure 4: Principals', teachers' and PA chairpersons' response on subject 2 highest performance improvement in 5 years

Source: Principals' questionnaire, teachers' questionnaire and PA chairpersons' questionnaire 
From Figure 4, most of the respondents $(94.7 \%$ of PA chairpersons, $91.7 \%$ of teachers and $91.2 \%$ of principals maintained that subject 2 selected by schools for improvement between 2014 and 2018 had fluctuating performance while $7 \%$ of both principals and teachers and 3.5\% of PA chairpersons concurred that subject 2 had improved by mean of 1.00 . Further, less than $2 \%$ of all the category of respondents indicated improvement by less than mean of 1.00 .

The finding confirms that majority of the sampled schools had the performance of subjects prioritized number 2 fluctuating but with improvement. This implies concerted efforts in these schools to improve academically.

(c) Highest Subject 3 Performance Improvement from 2014 to 2018

Highest subject 3 performance improvement from 2014 to 2018 refers to highest performance in the subjects which sampled schools had given priority number 3 for improvement during the indicated period. Majority had prioritized Chemistry and Biology while others had indicated Physics and other subjects as found in Table 2. This information is important because improvement in these subjects would be an indication that the students were positively benefiting and that would improve grade promotion and retention rates hence internal efficiency which was an independent variable for the study. The principals, teachers and PA chairpersons were therefore requested to indicate the performance of the selected subject 3 to help the researcher in working out the highest performance improvement level from 2014 to 2018. The results based on the responses are as presented in Figure 5 .

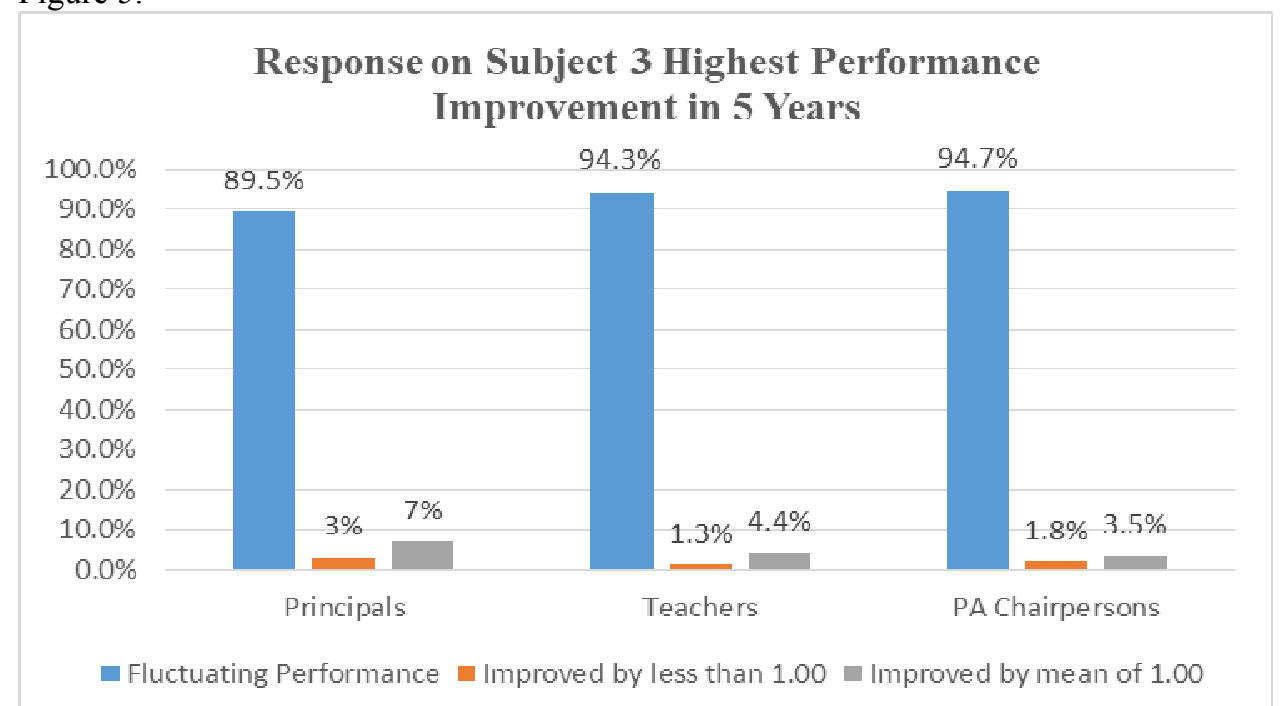

Figure 5: Principals', teachers' and PA chairpersons' response on subject 3 highest performance improvement in 5 years

Source: Principals' questionnaire, teachers' questionnaire and PA chairpersons' questionnaire

From Figure 5, most of the respondents $(94.7 \%$ of PA chairpersons, $94.3 \%$ of teachers and $89.5 \%$ of principals) concurred that subject 3 selected by schools for improvement had fluctuating performance while $7 \%$ of the principals, $4.4 \%$ of teachers and $3.5 \%$ of PA chairpersons indicated an improvement by mean of 1.00 . Lastly, $3.5 \%$ of principals, $1.8 \%$ of PA chairpersons and $1.3 \%$ of teachers noted improvement by mean of 1.00 . This finding also reveals that majority of the sampled schools had performance in the third targeted subjects fluctuating but with improvement.

These findings were complemented by qualitative findings from interview respondents, document analysis and observation sheet. It was established that the three prioritized subjects had fluctuating improvement but there was concerted effort from every player to have the performance of these subjects improved. One of the principals had this to say:

Definitely, we have achieved a lot. Just to remind you that in 2016, our school was the best school in chemistry in the whole of Sub-county with a mean of 5.5 that was the highest in the sub county and cannot be taken for granted. However, we have challenges in mathematics, but we are improving. Highest positive deviation we've had in mathematics I think it was 1.2 in 2015 but again dropped by 0.2 in 2016 (P6).

The sentiment was given support by the teachers as one of them averred that:

A big improvement has been made on mathematics, work is still on progress but in mathematics greatest improvement not by much but rising improvement in mathematics and also in Biology (T23).

From both quantitative and qualitative results it is clear that all the three subjects selected had fluctuating performance. The results presented, therefore, demonstrate that subject performance still required a lot of efforts 
and new strategies in the study locale. This begs the question of: what were the achieved key performance indicators in curriculum and instruction which were intended to improve the performance in these subjects?

(iii) Achieved Key Performance Indicators in Curriculum and Instruction

To ensure improvement in the three prioritized subjects and academic performance generally, sampled schools had strategies whose implementations had to be monitored through achievement of Key Performance Indicators. The study considered this information because the achieved Key performance Indicators are what confirm the implementation of strategic plan and the achieved KPIs in Curriculum and Instruction have direct influence on grade promotion and retention rates hence internal efficiency. The principals, teachers and PA chairpersons were as such asked to indicate whether the given activities under curriculum and instruction were completed or ongoing as an illustration of level of achievement of key performance indicators.

(a) Availing Text Books Activity

Text books are the key learning materials which are used by both teachers and students in teaching and learning process. Status of availing text books is significant to this study because according to Otieno (2015), availability of good text books is one of the significant factors which influence students' progression hence internal efficiency which is the dependent variable of this study. The principals, teachers and PA chairpersons were asked to indicate whether availing text books was a completed or an ongoing activity. Their responses are as presented in Figure 6.

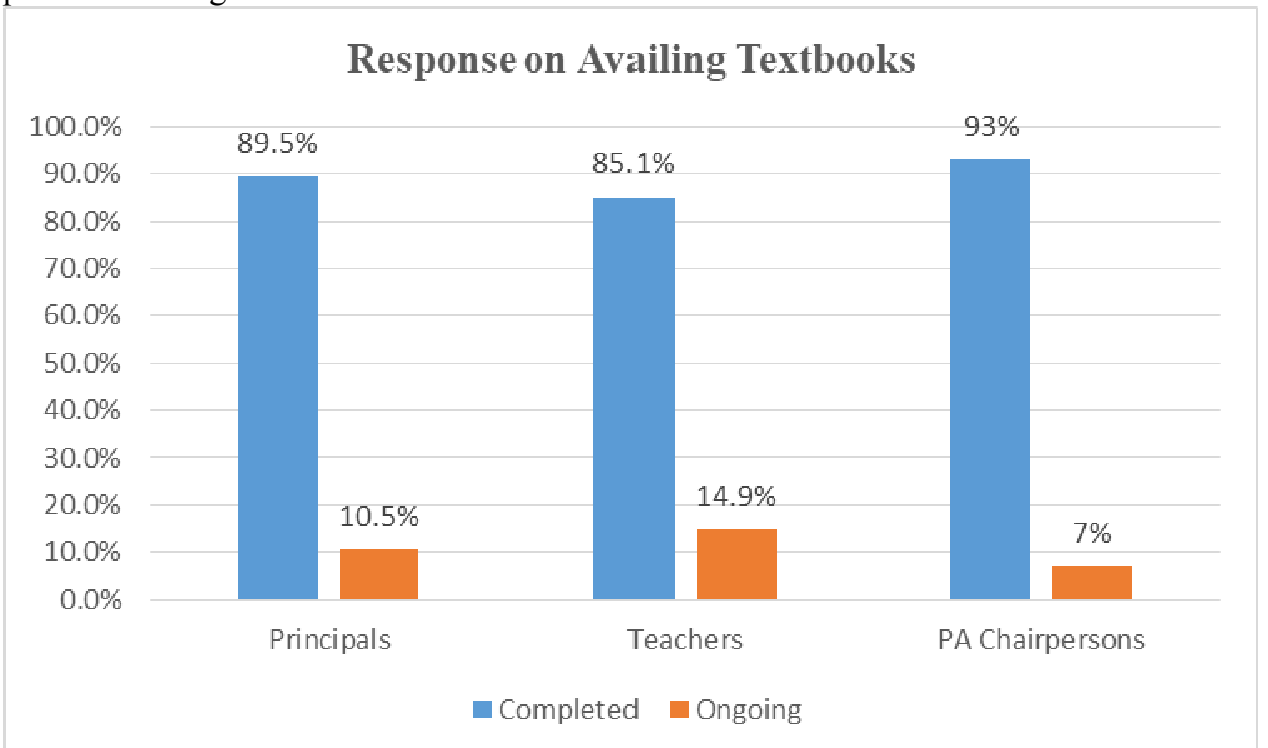

Figure 6: Principals, teachers and PA chairpersons response on availing text books

Source: Principals' questionnaire, teachers' questionnaire and PA chairpersons' questionnaire

From Figure 6, most of the respondents (93\% of PA chairpersons, $89.5 \%$ of principals and $85.1 \%$ of teachers) concurred that availing text books was a completed activity while $14.9 \%$ of teachers, $10.5 \%$ of principals and $7 \%$ of PA chairpersons was still an ongoing activity.

This finding implies that there were adequate text books for the three prioritized subjects in the majority of the sampled schools. This means that both the students and teachers did not strain in their learning and teaching activities respectively. This finding perhaps offers explanation for fluctuating but improved performance and hence noted increased grade promotion and retention rates.

(b) Availing Revision Books Activity

Revision Books are the key supplementary learning materials which are used by both teachers and students in reviewing the concepts which have been learnt and taught during normal class learning lesson. Status of availing revision books is significant to this study because availability of adequate revision books enables the students to overlearn the taught and learnt concepts. This ultimately influences students' progression hence internal efficiency which is the dependent variable of this study. The principals, teachers and PA chairpersons were asked to indicate whether availing revision books was a completed or an ongoing activity. Their responses are as presented in Figure 7. 


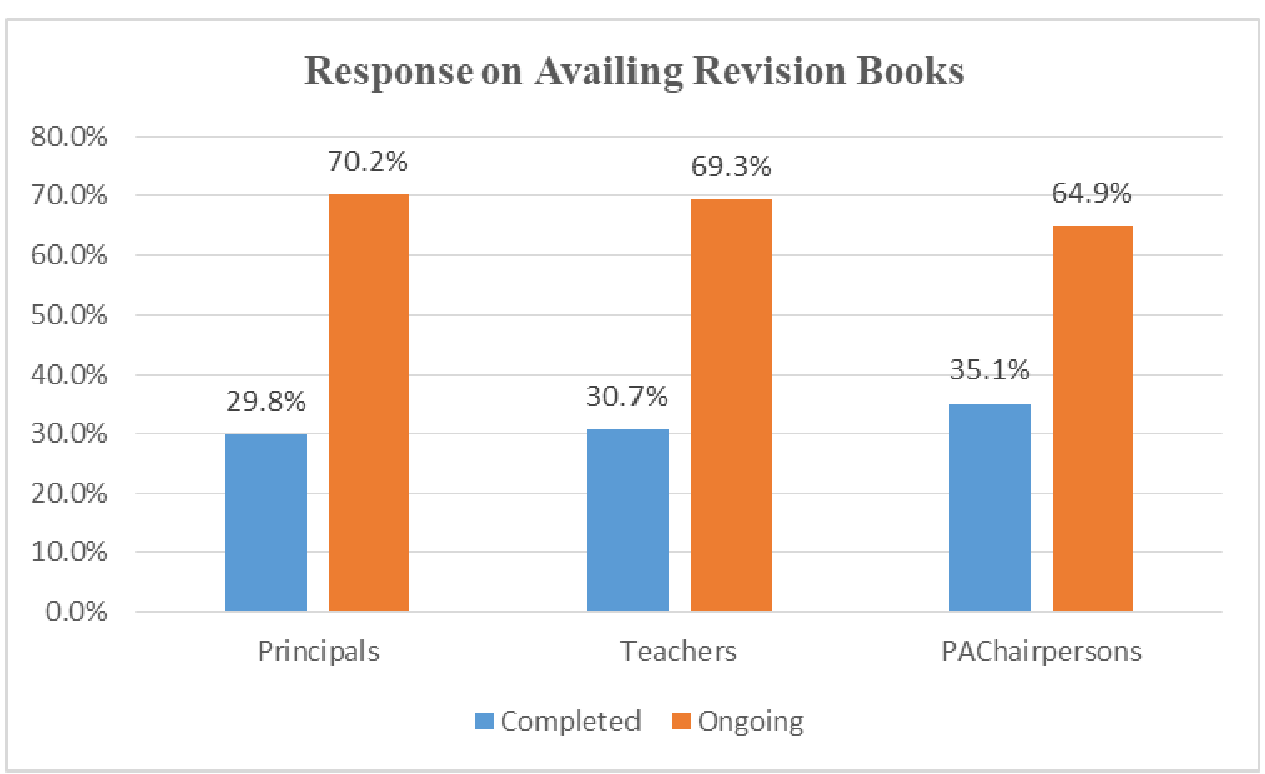

Figure 7: Principals, teachers and PA chairpersons response on availing revision books

Source: Principals' questionnaire, teachers' questionnaire and PA chairpersons' questionnaire

From Figure 7, majority of the respondents $(70.2 \%$ of principals, $69.3 \%$ of teachers and $64.9 \%$ of PA chairpersons) concurred that availing revision books was still an ongoing activity while $35.1 \%$ of PA chairpersons, $30.7 \%$ of teachers and $29.8 \%$ of principals confirmed that availing revision books was a completed activity.

The finding reveals that majority of the sampled schools was still going on with the availing of revision books. This implied that teachers strained to provide the students extra work to overlearn the taught and learnt concepts. This could have negative influence on progression of the students as had been established by Charles (2009) that inadequacy of such resources is a hindrance in attainment of quality objective of education.

\section{(c) Improving Pedagogy Activity}

Improving pedagogy in this study refers to the process of improving the teachers teaching methods and techniques through deliberate School-Based In-Service, Education and Training (INSETs). This information is important to this study because growth in teacher performance and professional development are crucial in improving classroom practice and teaching, which ultimately improves student achievement (Baloglu, et al. 2008, Wanjala, et al., 2014) hence internal efficiency. Which was a dependent variable in this study. The principals, teachers and PA chairpersons were in this regard, asked to indicate whether improving pedagogy was a completed or an ongoing activity. Their responses were as presented in Figure 8.

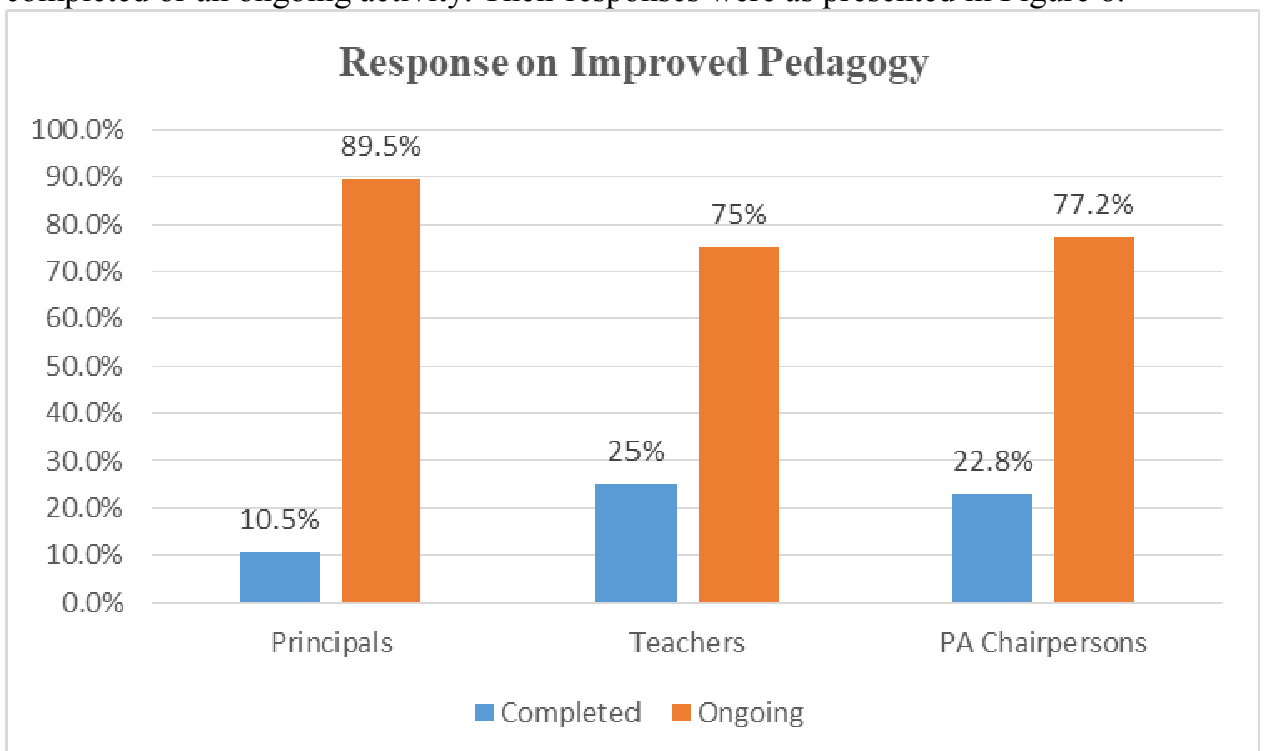

Figure 8: Principals, teachers and PA chairpersons response on improved pedagogy

Source: Principals' questionnaire, teachers' questionnaire and PA chairpersons' questionnaire

From Figure 8 , majority of the respondents $(89.5 \%$ of principals, $77.2 \%$ of PA chairpersons and $75 \%$ of 
teachers) confirmed that improving pedagogy was still an ongoing activity while $25 \%$ of teachers, $22.8 \%$ of PA chairpersons and $10.5 \%$ of principals indicated that it was a completed activity. The finding reveals that majority of the schools did not expedite the pedagogical activity which could seriously affected the classroom practice hence students' progression. This finding is supported by Wanjala, et al. (2014) that some strategic plans display ineffective programmes to establish professional development when this is the crucial area in enhancing student performance. Yet this is what ultimately leads to grade promotion and retention hence internal efficiency.

(d) Improving student/teacher ratio

Student/teacher ratio is considered to mean the number of students per teacher in a given class for classroom instruction. This information is important because earlier studies had confirmed that student/teacher is a more significant factor affecting promotion of learners (Otieno, 2014) hence internal efficiency which was the dependent variable for this study. The principals, teachers and PA chairpersons were therefore asked to indicate whether improving student: teacher ratio was a completed or an ongoing activity. Their responses are as presented in Table 3.

Table 3: Principals, teachers and PA chairpersons response on improved student: teacher ratio

$$
\text { Principals Teachers PA Chairpersons }
$$

\begin{tabular}{|c|c|c|c|c|c|c|}
\hline Status & $\mathbf{N}_{1}$ & $\%$ & $\mathbf{N}_{2}$ & $\%$ & $\mathbf{N}_{3}$ & $\%$ \\
\hline Completed & 14 & 24.6 & 77 & 33.8 & 17 & 29.8 \\
\hline Ongoing & 43 & 75.4 & 151 & 66.2 & 40 & 70.2 \\
\hline Total & 57 & 100 & 228 & 100 & 57 & 100 \\
\hline
\end{tabular}

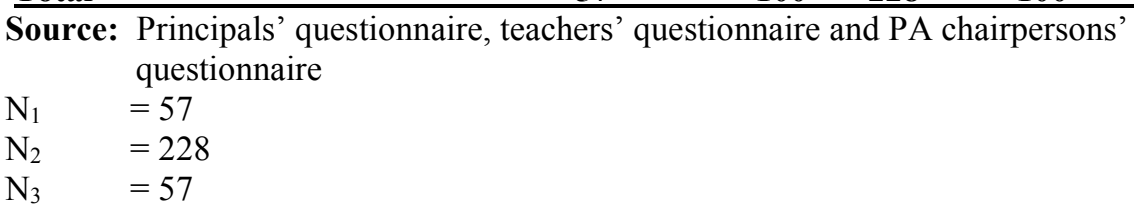

From Table 3, majority of the respondents (75.4\% of principals, $70.2 \%$ of PA chairpersons and $66.2 \%$ of teachers) indicated that improved student: teacher ratio was still an ongoing process while $33.8 \%$ of teachers, $29.8 \%$ of PA chairpersons and $24.6 \%$ of principals noted that it was a completed activity. The finding implies that employing more teachers to help improve the student/teacher ratio amidst exponential rise in the number of students in majority of the sampled schools was still a challenge to both BOM and the government. This may require deliberate commitment by both parties to come up with a policy which can help fast track the improvement of student/teacher ratio.

This finding is in tandem with the report by Adepoju, et al. (2011) that man state governments in Nigeria have made several attempts to make it a policy not to have more than 30 students per class in public secondary schools in order to improve the performance of students academically through effective curriculum delivery. The essence of such measures is to ensure students' progression and retention hence internal efficiency.

(e) Improving Student/Textbook ratio Activity

Student/Textbook ratio refers to the number of students sharing on book. Status of improving student/text books ratio is significant to this study because improved ratio means the books are adequate and leads to attainment of qualitative objective of education hence internal efficiency which was dependent variable of this study. This is in reference to Charles (2009) that inadequate provision of teaching and learning resources such as textbooks greatly hinders the attainment of qualitative objective of education.

The principals, teachers and PA chairpersons were thus asked to indicate whether improving student: textbook ratio was a completed or an ongoing activity. Their responses are as presented in percentages in Figure 9. 


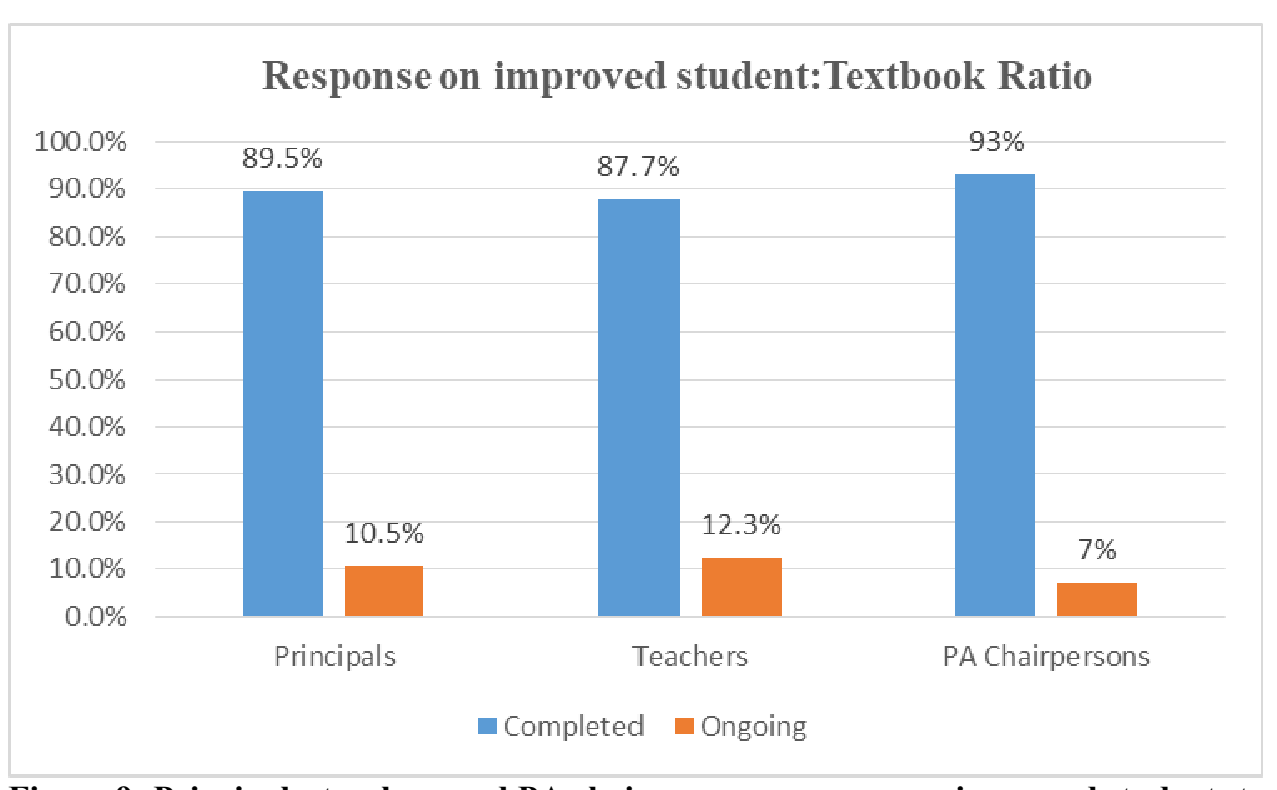

Figure 9: Principals, teachers and PA chairpersons response on improved student: textbook ratio

Source: Principals' questionnaire, teachers' questionnaire and PA chairpersons' questionnaire. and PA chairpersons' questionnaire

From Figure 9, most of the respondents (93\% of PA chairpersons, $89.5 \%$ of principals and $87.7 \%$ of teachers) indicated that improved student: textbook ratio was still an ongoing activity while $12.3 \%$ of teachers, $10.5 \%$ of principals and $7 \%$ of PA chairpersons concurred that it was a completed activity.

The finding reveals an impressive scenario in most of sampled public secondary schools that textbooks were available and were being utilized among the students at an improved ratio. This ultimately led to improved academic performance in various targeted subjects though at a fluctuating rate. It therefore means that adequate textbooks shared at an improved ratio among students will lead to improved student progression and retention hence internal efficiency. This is an attainment of quality objective of education (Charles 2009; Otieno, 2014).

\section{(f) Improving Students' Library Activity}

Students' library activity refers to the academic work given to the students which involves library research. This makes students critical and creative in their reasoning and ultimately builds their capacity to perform better in academic work leading to improved grade promotion and retention hence internal efficiency. The principals, teachers and PA chairpersons were as such asked to indicate whether improving students' library work was a completed or an ongoing activity. Their responses are as presented in Table 4.

Table 4: Principals, teachers and PA chairpersons 'response on improved students' library work

$$
\begin{array}{lll}
\text { Principals } & \text { Teachers } & \text { PA Chairpersons }
\end{array}
$$

\begin{tabular}{|c|c|c|c|c|c|c|}
\hline Status & $\mathbf{N}_{1}$ & $\%$ & $\mathbf{N}_{2}$ & $\%$ & $\mathbf{N}_{3}$ & $\%$ \\
\hline Completed & 6 & 10.5 & 35 & 15.4 & 10 & 17.5 \\
\hline Ongoing & 51 & 89.5 & 193 & 84.6 & 47 & 82.5 \\
\hline Total & 57 & 100 & 228 & 100 & 57 & 100 \\
\hline
\end{tabular}

Source: Principals' questionnaire, Teachers' questionnaire and PA chairpersons' questionnaire

$\mathrm{N}_{1} \quad=57$

$\mathrm{N}_{2} \quad=228$

$\mathrm{N}_{3} \quad=57$

From Table 4 , majority of respondents $(89.5 \%$ of principals, $84.6 \%$ of teachers and $82.5 \%$ of PA chairpersons) confirmed that improved students library work was still an ongoing activity while $17.5 \%$ of PA chairpersons, $15.4 \%$ of teachers and $10.5 \%$ of principals indicated that it was an ongoing activity. This finding reveals that majority of the sampled schools were still struggling with improving students' library work which could help improve their capacity to progress and consequently be retained in school. This perhaps could be because these schools had not constructed libraries. Such scenario has adverse effect on grade promotion and retention rates as corroborated by Sang, et al (2013) in their conclusion that repetition and drop out, which are opposite of grade promotion and retention, are higher in schools with inadequate infrastructure.

(iv) Participation in Co-Curricular Activities

Participation in co-curricular activities refers to schools allowing their students to take part in non- academic 
activities which are under Curriculum and Instruction. This information is significant to this study as it was a confirmation that the schools had comprehensive strategic plans which focus on the goal of developing an all round student (Reeves,2008; Rumelt, 2011). The principals, teachers and PA chairpersons were thus requested to indicate whether their schools participated in co-curricular activities or not. Their responses are as shown in Figure 10.

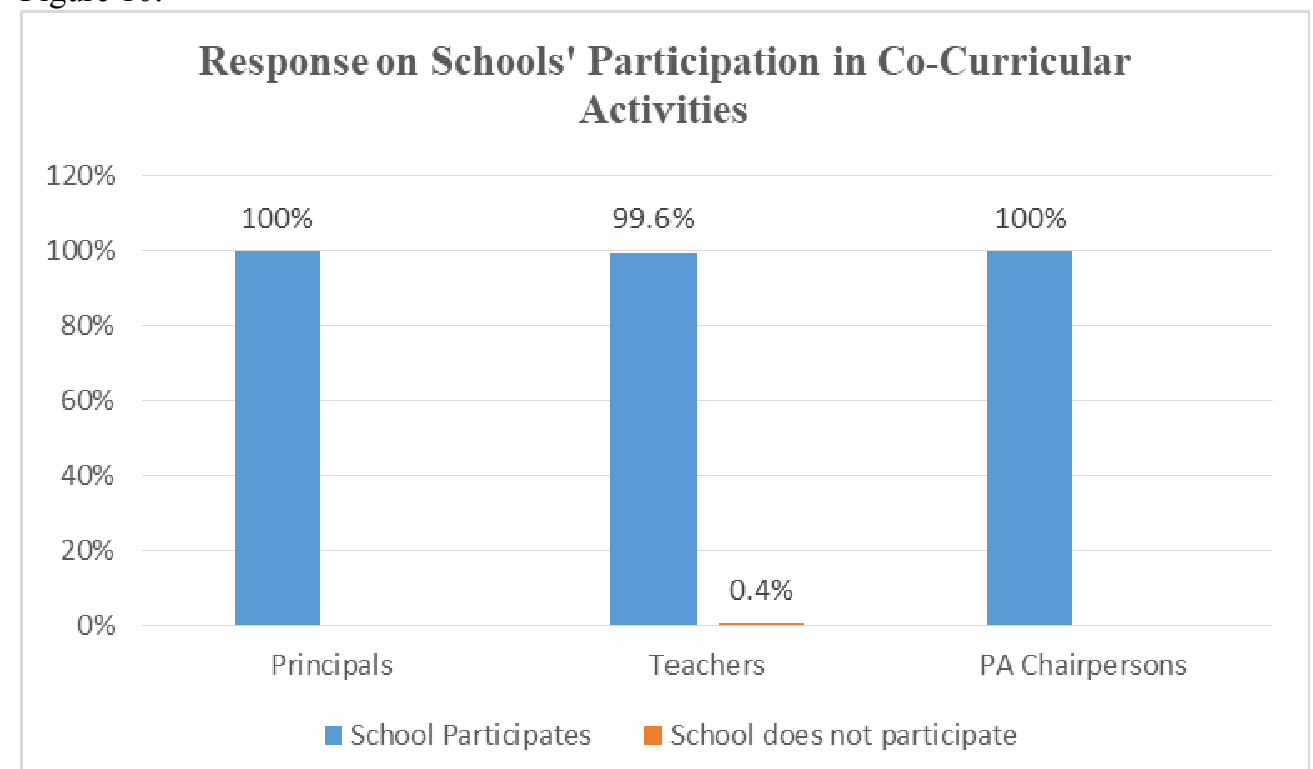

Figure 10: Principals, teachers and PA chairpersons responses on schools participation in co-curricular activities

Source: Principals' questionnaire, teachers' questionnaire and PA chairpersons' questionnaire

From Figure 10 , most of the respondents $(100 \%$ of principals, $100 \%$ of PA chairpersons and $99.6 \%$ of teachers confirmed that schools participated in co-curricular activities while $0.4 \%$ of teachers indicated that their school did not participate in co-curricular activities. The finding reveals that almost all the sampled public secondary schools participated in co-curricular activities. This means that schools had comprehensive strategic plans, as opposed to uncomprehensive plans, which they were implementing. Such plans take care of the needs of all students in terms of both academic and co-curricular so that the society can have all - round individuals.

This finding concurs with the argument of other researchers that some schools do not have comprehensive plans because they not only focus on material resources for the school such as buses and building, ignoring teaching and learning but also lay great emphasis on the results of paper and pencil tests, thereby ignoring the goal of developing an all - round student (Reeves, 2008; Rumelt, 2011; Wanjala, et al., 2014).

\section{(v) Highest Level Reached in Co-Curricular Activities}

Highest level reached in co-curricular activities refers to the top most level a school reached during competition with other schools in a particular activity. This information is of significance to this study because a student who competed in an activity up to a certain level would be motivated to remain and continue with schooling. The principals, teachers and PA chairpersons were therefore requested to indicate the highest level of participation reached by their schools in various co-curricular activities. The responses are as indicated in subsequent Figures and Tables.

\section{(a) Highest Level Reached in Football Activity}

Highest level reached in Football activity refers to the top most level that a particular school reached during ball games competition. This information is important to this study because Football as an activity at least made some students who could have dropped out of school to continue with learning. This is retention hence internal efficiency which was the dependent variable for this study. The principals, teachers and PA chairpersons were therefore requested to indicate the highest level of participation reached by their schools in Football activity. The responses are indicated in Figure 11. 


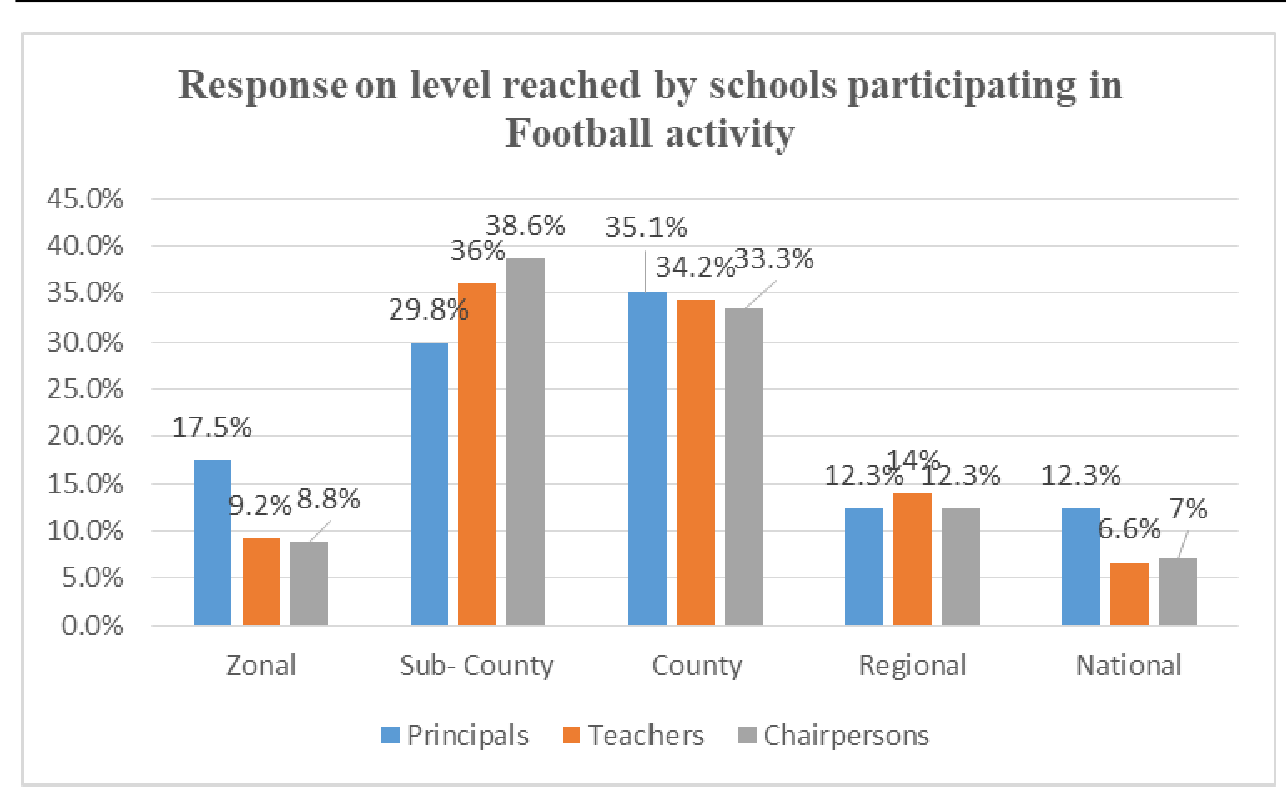

Figure 11: Principals, teachers and PA chairpersons response on level reached by schools participation in Football activity

Source: Principals' questionnaire, teachers' questionnaire and PA chairpersons' questionnaire

From Figure 11, 36.8\% of PA chairpersons, 36\% of teachers and $29.8 \%$ of principals indicated that their schools reached Sub-County level while $35.1 \%$ of principals, $34.2 \%$ of teachers and $33.3 \%$ of PA chairpersons confirmed that their schools reached county level in participating in Football. There were also schools which reached just zonal level as indicated by $17.5 \%$ of principals, $10.5 \%$ of PA chairpersons and $9.2 \%$ of teachers while other schools reached regional and national levels as indicated by $14 \%$ of teachers, $12.3 \%$ of both principals and PA chairpersons; and $7 \%$ of PA chairpersons, $6.6 \%$ of teachers and $5.3 \%$ of principals respectively.

The result reveals that each school participated in Football activity up to the level that was commensurate to the best ability of their players. This means that schools were concerned about the development of interest and talent of all students such that even those who were weak academically but talented in Football continued with their school life. It enabled the sampled schools to produce all - round students. The result therefore places the schools in category different from the one of schools without comprehensive strategic plans which lay great emphasis on the results of paper and pencil tests, hence ignoring the goal of developing all - round student (Wanjala, et al., 2014).

\section{(b) Highest Level Reached in Netball Activity}

Highest level reached in Netball activity refers to the top most level that a particular school reached during Netball games competition. This information is important to this study because Netball as an activity at least made some students who could have dropped out of school to continue with learning. This is retention hence internal efficiency which was the dependent variable for this study. The principals, teachers and PA chairpersons were therefore requested to indicate the highest level of participation reached by their schools in Netball activity. The responses are as indicated in Table 5.

Table 5: Principals, teachers and PA chairpersons response on level reached by schools in Netball activity

\begin{tabular}{lllllll}
\hline & \multicolumn{3}{l}{ Principal } & \multicolumn{2}{c}{ Teachers } & \multicolumn{2}{c}{ PA Chairpersons } \\
\cline { 2 - 7 } & $\mathbf{N}_{\mathbf{1}}$ & $\mathbf{\%}$ & $\mathbf{N}_{\mathbf{2}}$ & $\mathbf{\%}$ & $\mathbf{N}_{\mathbf{3}}$ & $\mathbf{\%}$ \\
\hline Zonal & 13 & 22.8 & 39 & 17.1 & 12 & 21.0 \\
Sub- County & 22 & 38.5 & 92 & 40.4 & 18 & 31.6 \\
County & 10 & 17.5 & 41 & 18.0 & 12 & 21.0 \\
Regional & 3 & 5.3 & 18 & 7.9 & 5 & 8.8 \\
National & 1 & 1.8 & 6 & 2.6 & 1 & 1.8 \\
Not participated & 3 & 5.3 & 13 & 5.7 & 3 & 5.3 \\
Not sure & 5 & 8.8 & 19 & 8.3 & 6 & 10.5 \\
\hline Total & $\mathbf{5 7}$ & $\mathbf{1 0 0}$ & $\mathbf{2 2 8}$ & $\mathbf{1 0 0}$ & $\mathbf{5 7}$ & $\mathbf{1 0 0}$ \\
\hline
\end{tabular}

Source: Principals' questionnaire, teachers' questionnaire and PA chairpersons' questionnaire

$\begin{array}{ll}\mathrm{N}_{1} & =57 \\ \mathrm{~N}_{2} & =228 \\ \mathrm{~N}_{3} & =57\end{array}$


From Table 5, majority of respondents $(40.4 \%$ of teachers, $38.5 \%$ of principals and $31.6 \%$ of PA chairpersons) confirmed that their schools reached sub- county level in participating in Netball while $21.1 \%$ of PA chairpersons and $17.5 \%$ of both principals and teachers concurred that their schools reached county level. There were also schools which reached just zonal level as indicated by $22.8 \%$ of principals, $21.1 \%$ of PA chairpersons and $17.1 \%$ of teachers while others reached regional and national levels as indicated by $8.8 \%$ of PA chairpersons, $8.3 \%$ of teachers and $5.3 \%$ of principals; and $2.6 \%$ of teachers and $1.8 \%$ of both principals and PA chairpersons respectively. Further, there were schools which did not participate in Netball but they were either Girls schools or Mixed schools as indicated by $5.7 \%$ of teachers and $5.3 \%$ of both principals and PA chairpersons while in other schools Netball was not applicable because they were Boys schools as indicated by $10.6 \%$ of PA chairpersons, $8.8 \%$ of principals and $8.3 \%$ of teachers.

The results reveal that all the Girls and Mixed Schools participated in Netball. This means all the girls who were in the sampled public secondary schools and had talent in Netball were given the opportunity to develop their talents and played up to the level that was commensurate to their abilities. This was intended to develop all - round students and all also to keep in school the girls who were weak academically (Wanjala, et al., 2014).

(c) Highest Level Reached in Volleyball Activity

Highest level reached in Netball activity refers to the top most level that a particular school reached during Netball games competition. This information is important to this study because Netball as an activity at least made some students who could have dropped out of school to continue with learning. This is retention hence internal efficiency which was the dependent variable for this study.

The principals, teachers and PA chairpersons were requested to indicate the highest level of participation reached by their schools in Volleyball activity. The responses were as indicated in percentages in Figure 12.

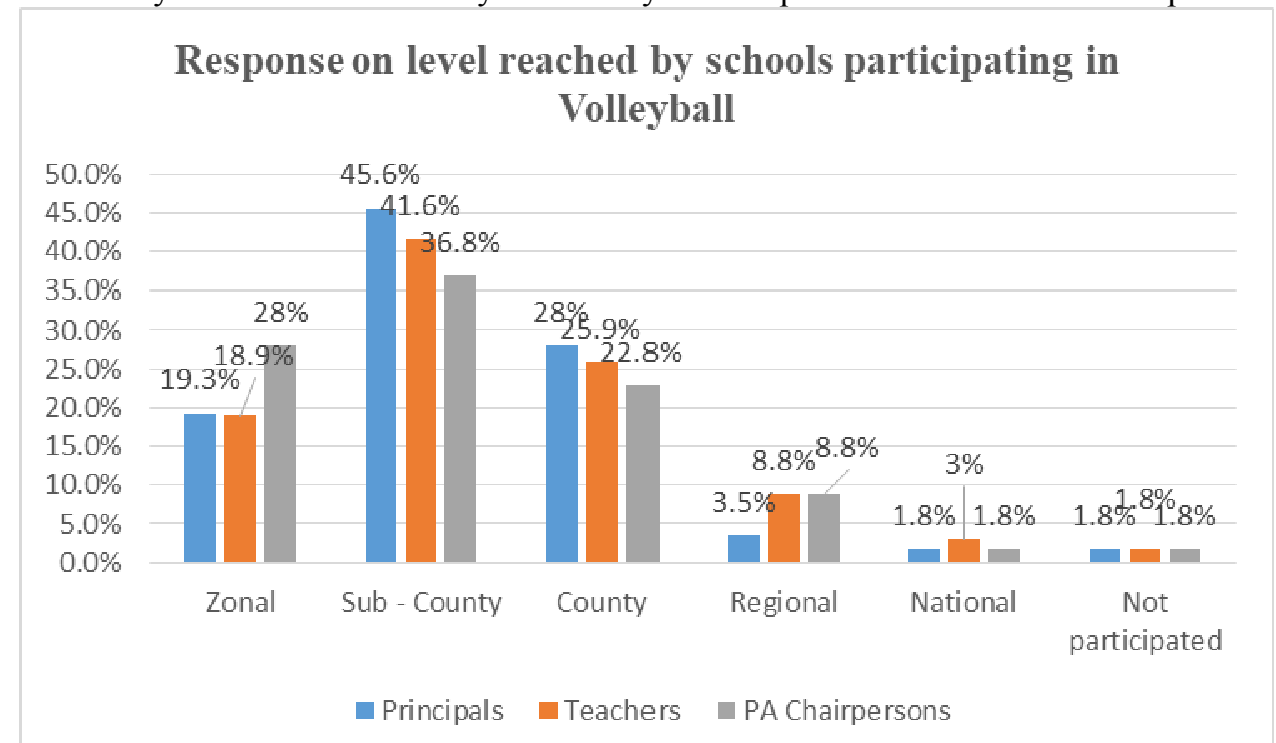

Figure 12: Principals, teachers and PA chairpersons response on level reached by schools participating in Volleyball

Source: Principals' questionnaire, teachers' questionnaire and PA chairpersons' questionnaire 


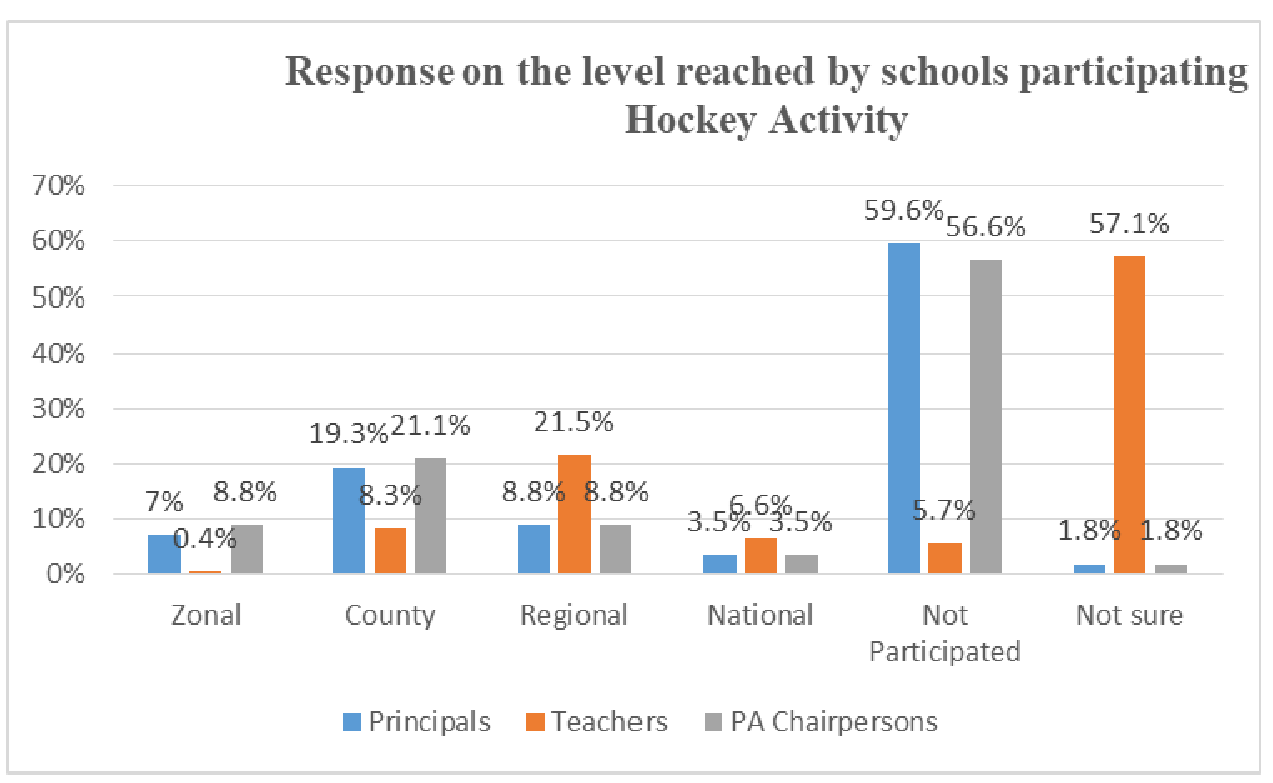

Figure 13: Principals, teachers and PA chairpersons response on level reached by schools participating in hockey activity

Source: Principals' questionnaire, teachers' questionnaire and PA chairpersons' questionnaire

From Figure 12, majority of respondents (45.6\% of principals, $41.7 \%$ of teachers and $36.8 \%$ of PA chairpersons confirmed that their schools reached sub-county level in Volleyball while $28.1 \%$ of principals, $25.9 \%$ of teachers and $22.8 \%$ of PA chairpersons indicated they schools reached county level. There were schools which reached zonal level as indicated by $28.1 \%$ of PA chairpersons, $19.3 \%$ of principals and $18.9 \%$ of teachers while other schools reached regional level and national level as indicated by $8.8 \%$ of both teachers and PA chairpersons and $3.1 \%$ of principals; and $3.1 \%$ of teachers and $1.8 \%$ of both principals and PA chairpersons respectively. Finally, $1.8 \%$ of all the categories of the respondents concurred that their schools did not participate in Volleyball.

\section{(d) Highest Level Reached in Basketball Activity}

Highest level reached in Basketball activity refers to the top most level that a particular school reached during Basketball games competition. This information is important to this study because Basketball as an activity at least made some students who could have dropped out of school due to poor academic performance continue with learning. This is retention hence internal efficiency which was the dependent variable for this study. The principals, teachers and PA chairpersons were therefore requested to indicate the highest level of participation reached by their schools in Basketball activity. The responses are as indicated in Table 6 .

Table 6: Principals, teachers and PA chairpersons response on level reached by schools participating in Basketball activity

\begin{tabular}{lllllll}
\hline & Principals & \multicolumn{3}{c}{ Teachers } & \multicolumn{2}{c}{ PA Chairpersons } \\
\cline { 2 - 7 } Status & $\mathbf{N}_{\mathbf{1}}$ & $\mathbf{0}$ & $\mathbf{N}_{\mathbf{2}}$ & $\mathbf{\%}$ & $\mathbf{N}_{\mathbf{3}}$ & $\mathbf{\%}$ \\
\hline Zonal & 2 & 3.5 & 6 & 2.6 & 1 & 1.8 \\
Sub - County & 8 & 14.0 & 36 & 15.8 & 9 & 15.8 \\
County & 11 & 19.3 & 39 & 17.1 & 12 & 21.0 \\
Regional & 1 & 1.8 & 8 & 3.5 & 2 & 3.5 \\
National & 1 & 1.8 & 5 & 2.2 & 1 & 1.8 \\
Not participated & 34 & 59.6 & 59.6 & 58.3 & 31 & 56.1 \\
\hline Total & $\mathbf{5 7}$ & $\mathbf{1 0 0}$ & $\mathbf{2 2 8}$ & $\mathbf{1 0 0}$ & $\mathbf{5 7}$ & $\mathbf{1 0 0}$ \\
\hline
\end{tabular}

Source: Principals' questionnaire, teachers' questionnaire and PA chairpersons' questionnaire

$\mathrm{N}_{1} \quad=57$

$\mathrm{N}_{2} \quad=228$

$\mathrm{N}_{3} \quad=57$

From Table 6 , majority of respondents $(58.3 \%$ of teachers, $57.9 \%$ of principals and $54.4 \%$ of PA chairpersons) indicated that their schools did not participate in Basketball while $21.1 \%$ of PA chairpersons, $19.3 \%$ of principals and $17.1 \%$ of teachers confirmed that their schools reached county level. Some schools reached sub-county level as indicated by $15.8 \%$ of PA chairpersons, $15 \%$ of teachers and $14 \%$ of principals while others reached zonal level as indicated by $3.5 \%$ of principals, $2.6 \%$ of teachers and $1.8 \%$ of PA chairpersons. There were schools which reached regional as indicated by $3.5 \%$ of both teachers and PA 
chairpersons and $1.8 \%$ of principals while $2.2 \%$ of teachers, $1.8 \%$ of both principals and PA chairpersons indicated that their schools reached national level. Finally, $1.8 \%$ of both principals and PA chairpersons and $0.4 \%$ of teachers indicated that they were not sure of the level their schools reached in Basketball.

The finding indicates that majority of the sampled schools did not participate in Basketball activity up to any level. This could have been because the students had no interest or there was not even a single teacher who could train Basketball.

\section{(e) Highest Level Reached in Hockey Activity}

Highest level reached in Hockey activity refers to the top most level that a particular school reached during Hockey games competition. This information is important to this study because Hockey as an activity at least made some students who could have dropped out of school to continue with learning. This is retention hence internal efficiency which was the dependent variable for this study. The principals, teachers and PA chairpersons were therefore requested to indicate the highest level of participation reached by their schools in Hockey activity. The responses are indicated in Figure 13.

From Figure 13, Majority (57.5\%) of teachers were not sure of the level their schools reached in participating in Hockey while majority of principals (59.6\%) and PA chairpersons $(56.1 \%)$ confirmed that their schools did not participate in hockey. Some schools reached county level as indicated by $21.1 \%$ of PA chairpersons, $19.3 \%$ of principals and $8.3 \%$ of teachers while others reached regional level as confirmed by $21.5 \%$ of teachers, $8.8 \%$ of both principals and PA chairpersons. There was a group of schools which managed only zonal level as indicated by $8.8 \%$ of PA chairpersons, $7 \%$ by principals and $0.4 \%$ of teachers while another group managed to reach national level as confirmed by $6.6 \%$ of teachers and $3.5 \%$ of both principals and PA chairpersons.

The results reveal that more than a half of the sampled schools did not participate in Hockey activity. This meant that either the students did not have interest and talent in Hockey or there was no teacher who had interest and expertise to train the students in this activity.

\section{(f) Highest Level Reached in Athletics Activity}

Highest level reached in Athletics activity refers to the top most level that a particular school reached during Athletics competition. This information is important to this study because Athletics as an activity at least made some students who could have dropped out of school to continue with learning. This is retention hence internal efficiency which was the dependent variable for this study. The principals, teachers and PA chairpersons were thus requested to indicate the highest level of participation reached by their schools in Athletics activity. The responses are as indicated in Table 7.

Table 7: Principals, teachers and PA chairpersons response on level reached by schools participating in Athletics activity

\begin{tabular}{|c|c|c|c|c|c|c|}
\hline \multirow[t]{2}{*}{ Status } & \multicolumn{2}{|c|}{ Principals } & \multicolumn{2}{|c|}{ Teachers } & \multicolumn{2}{|c|}{ PA Chairpersons } \\
\hline & $\mathbf{N}_{1}$ & $\%$ & $\mathbf{N}_{2}$ & $\%$ & $\mathbf{N}_{3}$ & $\%$ \\
\hline Zonal & 3 & 5.3 & 12 & 5.3 & 1 & 1.8 \\
\hline Sub - County & & & & & 5 & 8.8 \\
\hline County & 9 & 15.8 & 15 & 6.6 & 16 & 28.0 \\
\hline Regional & 17 & 29.8 & 84 & 36.8 & 18 & 31.6 \\
\hline National & 17 & 29.8 & 59 & 25.9 & 15 & 26.3 \\
\hline Not participated & 11 & 19.3 & 58 & 25.4 & 2 & 3.5 \\
\hline Total & 57 & 10 & 228 & 100 & 57 & 100 \\
\hline $\begin{array}{ll}\text { Source: } & \text { Princi } \\
N_{1} & =57 \\
N_{2} & =228 \\
N_{3} & =57\end{array}$ & laire & ers' q & naire & chair & & \\
\hline
\end{tabular}

From the Table 7, the same number of schools reached regional and national levels in athletics as indicated by $29.8 \%$ of principals. This was confirmed by $36.8 \%$ of teachers and $31.6 \%$ of PA chairpersons for regionals while for national level it was confirmed by $26.3 \%$ of PA chairpersons and $25.9 \%$ of teachers. There were some schools which did not participate in athletics at all as confirmed by $25.4 \%$ of teachers, $19.3 \%$ of principals and $3.6 \%$ of PA chairpersons while other schools just reached only zonal level as indicated by $5.3 \%$ of both principals and teachers and $1.8 \%$ of PA chairpersons. Finally, only $8.8 \%$ of PA chairpersons indicated that some schools reached county level in athletics.

The finding reveals that majority of the sampled schools participated in Athletics competition and their participants reached various levels which definitely motivated the students (both athletes and non- athletes) to continue identifying with the school up to the end of their Form Four course.

\section{(g) Highest Level Reached in Drama Activity}

Highest level reached in Drama activity refers to the top most level that a particular school reached during Drama Festivals competition. This information is important to this study because Drama as an activity at least 
made some students who could have dropped out of school to continue with learning. This is retention hence internal efficiency which was the dependent variable for this study. The principals, teachers and PA chairpersons were therefore requested to indicate the highest level of participation reached by their schools in Drama activity. The responses are indicated in Figure 14.

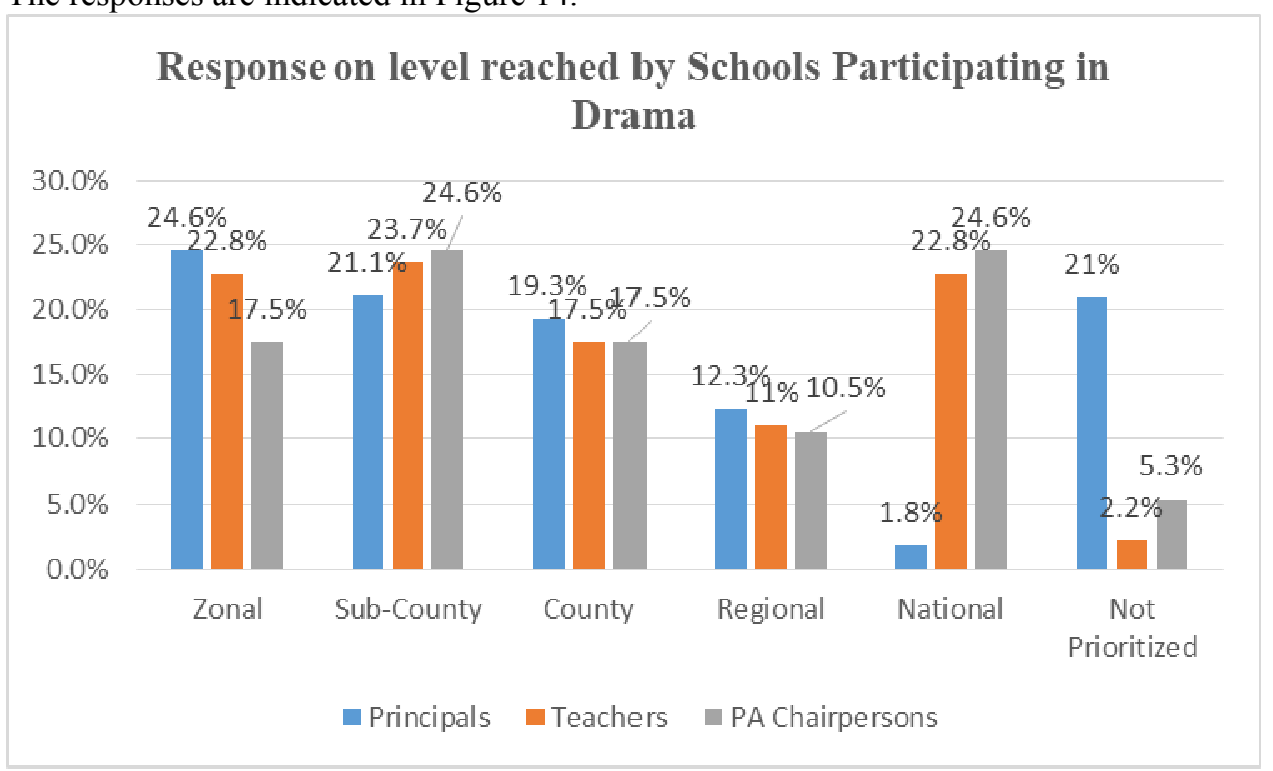

Figure 14: Principals, teachers and PA chairpersons responses on level reached by schools participating in drama activity

Source: Principals' questionnaire, teachers' questionnaire and PA chairpersons' questionnaire

Figure 14 illustrates that $24.6 \%$ of principals indicated that their schools reached zonal level in Drama which was confirmed by $22.8 \%$ of teachers and $17.5 \%$ of PA chairpersons while equal number of principals (21.1\%) indicated schools reaching both sub-county and county levels. This was confirmed by $24.6 \%$ of PA chairpersons and $23.7 \%$ of teachers for sub-county level while $17.5 \%$ of both teachers and PA chairpersons for county level. Finally, $5.3 \%$ of PA chairpersons, $2.2 \%$ of teachers and $1.8 \%$ of principals indicated that their schools reached national level while $24.6 \%$ of PA chairpersons, $22.8 \%$ of teachers and $21.1 \%$ of principals indicated that their schools did not participate in Drama.

The finding reveals that most of the sampled schools participated in Drama Festivals competitions and reached various levels. This was actually a motivator for students to work hard in order to progress and remain in school so that they could continue identifying with their schools.

\section{(h) Highest Level Reached in Rugby Activity}

Highest level reached in Rugby activity refers to the top most level that a particular school reached during Rugby games competition. This information is important to this study because Rugby as an activity at least made some students who could have dropped out of school to continue with learning. This is retention hence internal efficiency which was the dependent variable for this study. The principals, teachers and PA chairpersons were therefore requested to indicate the highest level of participation reached by their schools in Rugby activity. The responses are as indicated in Table 8.

Table 8: Principals, teachers and PA chairpersons response on level reached by schools participating in Rugby activity

$$
\begin{array}{lll}
\text { Principals } & \text { Teachers } & \text { PA Chairpersons }
\end{array}
$$

\begin{tabular}{|c|c|c|c|c|c|c|c|}
\hline Status & & $\mathbf{N}_{1}$ & $\%$ & & $\mathbf{N}_{2}$ & $\%$ & $\mathbf{N}_{3}$ \\
\hline Zonal & & 2 & 3.5 & & 10 & 4.4 & 3 \\
\hline Sub - County & & 4 & 7.0 & 18 & 7.9 & 5 & 8.8 \\
\hline County & & 5 & 8.8 & 24 & 10.5 & 6 & 10.5 \\
\hline Not participated & 46 & 80.7 & 176 & & 77.2 & 43 & 75.4 \\
\hline
\end{tabular}

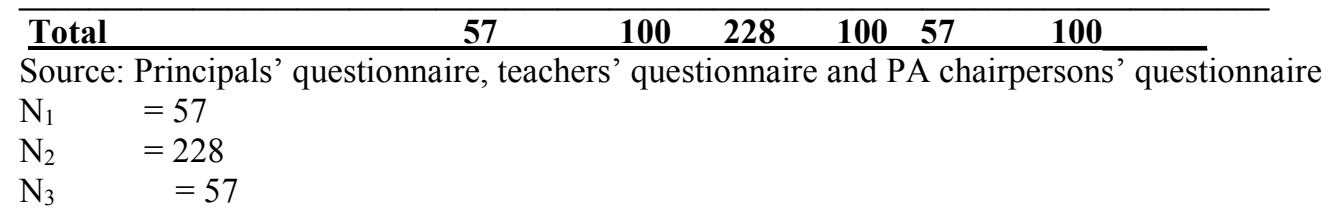


From Table 8 , majority of respondents $(78.9 \%$ of principals, $77.2 \%$ of teachers and $75.5 \%$ of PA chairpersons) confirmed that their schools did not participate in Rugby while $10.5 \%$ of principals, teachers and PA chairpersons confirmed that their schools reached county level in Rugby. There were some schools which reached sub-county level as indicated by $8.8 \%$ of PA chairpersons, $8.3 \%$ of teachers and $7 \%$ of principals while others reached zonal level as indicated by $5.3 \%$ of PA chairpersons, $3.9 \%$ teachers and $3.5 \%$ of principals.

The results reveal that majority of the sampled schools did not participate in Rugby perhaps because either the students were not interested and talented in Rugby or there was no teacher with expertise to train Rugby. Nevertheless, the schools which participated in Rugby gave the few talented and interested students opportunity to develop their talents and reason to continue identifying with their schools.

\section{(i) Highest Level Reached in Handball Activity}

Highest level reached in Handball activity refers to the top most level that a particular school reached during Handball games competition. This information is important to this study because Handball as an activity at least made some students who could have dropped out of school to continue with learning. This is retention hence internal efficiency which was the dependent variable for this study. The principals, teachers and PA chairpersons were as such, requested to indicate the highest level of participation reached by their schools in Handball activity. The responses are as indicated in percentages in Figure 15.

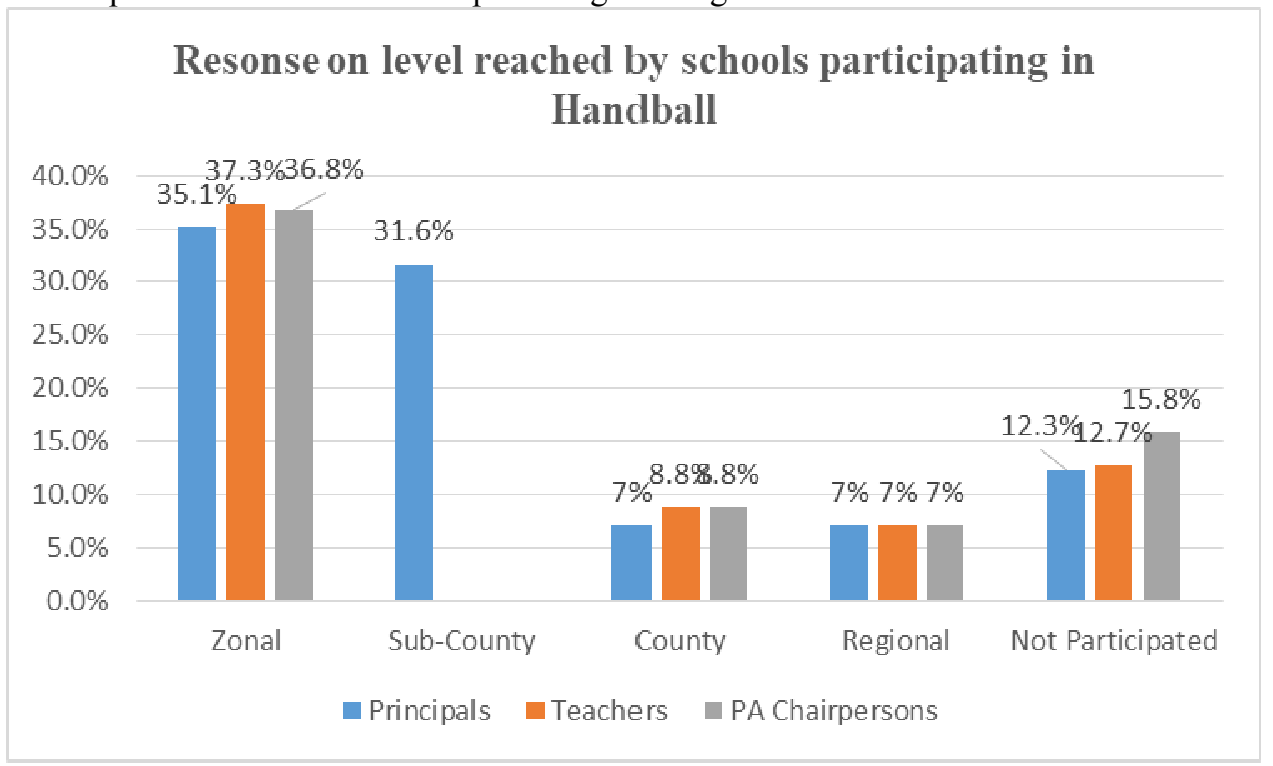

Figure 15: Principals, teachers and PA chairpersons response on level reached by schools participating in Handball activity

Source: Principals' questionnaire, teachers' questionnaire and PA chairpersons' questionnaire

From Figure 15, majority of principals $(38.6 \%)$ indicated that their schools reached sub-county level and this was confirmed by $34.2 \%$ of teachers and $31.6 \%$ of PA chairpersons while $35.1 \%$ of principals indicated that their schools reached zonal level and was also confirmed by $37.3 \%$ of teachers and $36.8 \%$ of PA chairpersons. While $12.3 \%$ of principals indicated that their schools did not participate in Handball confirmed by $15.8 \%$ of PA chairpersons and $12.7 \%$ of teachers, equal number of principals (7\%) indicated that their schools reached county and regional levels as confirmed by $8.8 \%$ and $7 \%$ of both teachers and PA chairpersons for county and regional levels respectively.

The finding reveals that majority of the sampled schools participated in Handball competition and their participants reached various levels which definitely motivated the students (both the Handball players and nonplayers) to continue identifying with the school up to the end of their Form Four course.

\section{(vi) Level of achievement of KPI in Curriculum and Instruction}

Having indicated level of achievement per activity which was strategized as whether complete or ongoing, it was important to establish the level of achievement of KPI in Curriculum and Instruction. Level of achievement of KPI in Curriculum and Instruction refers to the extent of the overall achievement of the Key Performance Indicators in Curriculum and Instruction following the observed achievement of KPI in every activity which had been earlier analyzed. This information is important because it was going to help in running the regression analysis between achieved KPI in Curriculum and Instruction and Internal Efficiency (Grade Promotion Rate and Retention Rate). The principals, teachers and PA chairpersons were therefore asked to rate the extent of achievement of KPI in Curriculum and Instruction in sampled public secondary schools in the study locale. Their responses are indicated in Figure 16. 


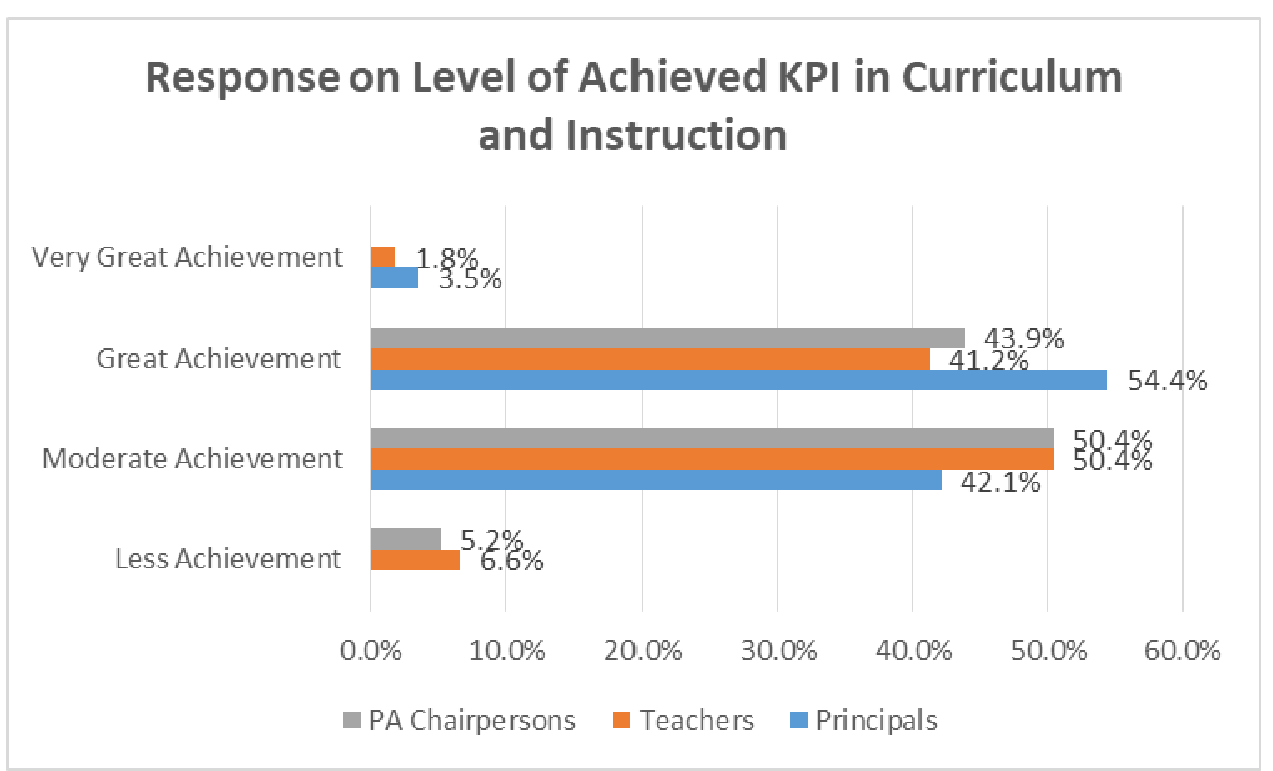

Figure 16 : Principals, teachers and PA chairpersons response on level of Achieved KPI in curriculum and instruction

Source: Principals' questionnaire, teachers' questionnaire

From Figure 16, majority of principals $(54.4 \%)$ indicated great achievement of KPI in curriculum and instruction while $42.1 \%$ of them indicated moderate achievement and $3.5 \%$ very great achievement. Majority of PA chairpersons $(50.9 \%)$ indicated moderate achievement while $43.9 \%$ indicated great achievement and $5.2 \%$ less achievement. On the side of teachers, majority (50.4\%) indicated moderate achievement while $41.2 \%$ great achievement, $6.1 \%$ less achievement, $1.8 \%$ very great achievement and $0.4 \%$ no achievement.

The finding reveals that majority of the schools had reached at least moderate level of achievement of KPIs in Curriculum and Instruction. This means that Curriculum and Instruction process was being conducted under the guidance of an organized system which makes it easy to determine the level of performance. This finding is given support by other literature which purport that strategic planning provides better performance of significance than unplanned, opportunistic adaptive approach (IIEP, 2010; Republic of South Africa, 2013).

The qualitative data generated through the interview, document analysis and observation schedule, summarize the status of key performance indicators in curriculum and instruction. The results that have been revealed by the interview guide, document analysis and observation schedule are that: a) most schools prioritize Maths, Chemistry, Biology and Physics for improvement; b) achieved strategies for improving the subjects are improved text book ratio through availing text books by the government, improved teacher student - contact time, improved pedagogy, improved library work, increased practicals in science, use of peer teaching; c) most schools participate in co-curricular activities because they want to produce all - round individuals as influenced by their vision and mission statements. This concurs with Wanjala, et al. (2014). The respondents had a lot to say this on this issue. For instance, one of the teachers averred that:

They are doing all they can by increasing the number of personnel in the department, equipping the lab and engaging the students on a number of practicals and joint exams to enhance that. The textbooks are available, the principal is really working to get textbooks especially the revision books, despite the fact that the government has now taken over the textbooks but we have seen him still struggling to inject more textbooks. There are a number of teachers who usually attend SMASSE, particularly science teachers. We have a number of workshops for different subjects. The school has freely come in to support (T26).

The principals as the managers of the schools gave their views on this matter and one of them reported that: For textbooks, we have a ratio of one to one, courtesy of the Government. I believe we have enough revision books. The methodology science teachers use IT. I think you can also see in my office here that is the projector; they also use the method of student centered approach. That is why I have said they are adhering towards more practicals. You know when the students understand the practical aspect of it, when it comes to theory, they will be able to be conversant. And also again the students are exposed through symposiums, we have attended symposium in Siaya County, Kisumu County we have even gone outside Kisumu County. In the library, we have a policy where students borrow books for a fortnight then they return and borrow another one (P1).

For the purpose of all-inclusivity, the PA chairpersons' voices were added to this view. One of them had this to say: 
As a school based on vision and mission to develop wholesome individual. We do not only incline towards academics alone, we also have the co-curricular activities and our school has participated and has been sponsored in a number of co-curricular activities and that is drama, which reached regional level this year. We have music, they also reached regional level, in sports we have volleyball, soccer, handball, hockey, rugby and basketball so there is variety and I forgot to mention the racket games that participant reached regional level. I remember sometimes back, drama managed to reach national. Athletics is part of competitive area, where the school posted students and they reached county level (PAC 3)

The results from both quantitative and qualitative findings concur that Mathematics and Science subjects, especially Chemistry and Biology need improvement of performance. This targeting has perhaps been influenced by either past poor performance or Government policy in relation to Science Technology Engineering Mathematics (STEM).

According to Rajput (2019), STEM is having critical position at the centre of Kenya's ability to attain Vision 2030. However, Kenya, like any other African countries, faces immense challenge in the field of STEM at all levels of education including secondary, in terms of performance, enrolment and gender disparity. This concurs with the findings about the performance, in the last five years, of the targeted subjects for improvement which was reported by the majority of the respondents to be fluctuating but with improvement.

The Effect of Achieved Key Performance Indicators in Curriculum and Instruction on Internal Efficiency To determine the effect of achieved key performance indicators in curriculum and instruction on internal efficiency in public secondary schools in the study locale, the researcher conducted regression analysis involving the second predictor of independent variable (achieved KPI in curriculum and instruction) and dependent variables (grade promotion rates and retention rates). The analysis was done in SPSS. The results are as presented in Table 9.

Table 9: Statistical measurement of the effect of achieved key performance indicators in curriculum and instruction on internal efficiency

\begin{tabular}{llcc}
\hline & Dependent variable: Internal efficiency & \\
\hline & \multicolumn{1}{c}{$\begin{array}{c}\text { Regression } \\
\text { Statistics }\end{array}$} & $\begin{array}{c}\text { Model 3 } \\
\text { Grade promotion rate }\end{array}$ & $\begin{array}{c}\text { Model 4 } \\
\text { Retention rate }\end{array}$ \\
\hline \multirow{3}{*}{ Predictor: Achieved } & $\mathrm{R}$ & .664 & .238 \\
Key performance indicators & R-squared $\left(\mathrm{R}^{2}\right)$ & .440 & .057 \\
In curriculum and instruction & Adjusted R-squared $\left(\mathrm{R}^{2}\right.$ adj) & .439 & .054 \\
& Beta $(\beta)$ & .669 & .249 \\
& Standard error of Est $(\varepsilon)$ & .47532 & .64123 \\
& Constant & .908 & 2.709 \\
& Durbin - Watson & 1.958 & 1.770 \\
\hline
\end{tabular}

Model 3 in Table 9 indicates data of a simple correlation between the predictor/independent variable component (Achieved Key Performance indicators in curriculum and instruction) and the first measure of the dependent variable (Grade Promotion Rate) in the sampled counties. The $\mathrm{R}^{2}$ squared $\left(\mathrm{R}^{2}\right)$ computed yielded a value of .440, suggesting that achieved key performance indicators in curriculum and instruction explained $44 \%$ of the variations in the Grade Promotion Rate in public secondary schools in the study locale. The adjusted $\mathrm{R}-$ squared $\left(\mathrm{R}^{2}\right.$ adj) also depicts that achieved key performance indicators in curriculum and instruction explained 43.9 percent variations in the Grade Promotion Rate and it is slightly lower than $\mathrm{R}^{2}$ predicted. The Beta weight $(\beta=669)$ value predicts that one unit of increase in achieved key performance indictor in curriculum and instruction is expected to cause .669 increase in Grade Promotion Rate in public secondary schools.

The constant value suggests that the predicted value of Grade Promotion Rate is .908 , if the value of the achieved key performance indicators in curriculum and instruction is zero. The standard error of estimate $(\varepsilon)$ was found to be .47532 , suggesting that there were other factors of magnitude .47532 that influence the grade promotion rate but not observed or taken into account. The Durbin - Watson test yielded a value of 1.958. A value approaching 2, as obtained in the model 3 means that there is no auto correlation in the sample values.

Model 4 presented in Table 9 shows data on the effect of achieved key performance indicators in the curriculum and instruction on retention rate in public secondary school in the study locale. The Pearson's R $=.238$ illustrates that there was a positive correlation between the achieved key performance indicators in curriculum and instruction and retention rate in sampled schools. The R-squared $\left(\mathrm{R}^{2}\right)$ computed gave a value of .057 , showing that achieved key performance indicators explained $5.7 \%$ of variations in the retention rate in public secondary schools in the study locale. The adjusted R-squared ( $\mathrm{R}^{2}$ adj) also indicates that achieved key performance indicators in curriculum and instruction explain 5.4\% variation in the retention rate and it is slightly lower than the $\mathrm{R}^{2}$ predicted. 
The Beta weight $(\beta=.249)$ value predicts that one unit increase in achieved key performance indicators in curriculum and instruction is expected to cause .249 increase in retention rate in public secondary schools in the study locale.

The constant value suggests that the predicted value of retention rate is 2.709 if the value of the achieved key performance indicators in curriculum and instruction is zero. The standard error of estimate $(\varepsilon)$ was found to be .64123 , suggesting that there were other factors of magnitude .64123 that influence the retention rate but not observed or taken into account. The Durbin Watson test yielded a value of 1.770. A value approaching 2, as obtained in model 4 means that there is no auto correlation in the sample value.

The finding reveals that there is a positive correlation between achieved key performance indicators (KPIs) in Curriculum and Instruction and grade promotion rate as well as retention rate. However, the correlation between the achieved KPIs and grade promotion rate was higher at .440 than between achieved KPIs and retention rate at .057 . This implies that the influence of achieved KPIs was greater on grade promotion rate than on retention rate as confirmed by the simple linear regression coefficients $\left(\mathrm{R}^{2}=.440\right.$ and .057 respectively). This means that achieved KPIs can influence $44 \%$ and $5.7 \%$ of grade promotion rate and retention rate respectively. It is also worth noting that one unit increase in achieved KPIs will cause .669 and .249 increase in Grade Promotion Rate and Retention Rate respectively.

The qualitative data generated through the interview, document analysis and observation schedule, summarize the status of key performance indicators in curriculum and instruction and the effect on internal efficiency. The result from the interview guide, document analysis and observation schedule is that: achieved key performance indicators have influence on grade promotion rate as well as retention rate in public secondary schools. For instance, one of the teachers had this to say:

It helps increase both grade promotion and retention rates (T25).

A principal supported the same view and stated that:

Yes the achieved KPI have helped improve grade promotion rates and also retention rates, nearly over ninety eight percent $(P 7)$.

Further, PA chairpersons equally gave insightful report on the matter and one of them averred that:

As a school we are foreseeing an improved enrolment and there is increased grade promotion rate as well as increased retention rates (PA 9).

The results from both quantitative and qualitative findings concur that the achieved key performance indicators have influence on grade promotion rate and retention rate in Public secondary schools. The findings corroborate the finding of a study by Otieno (2015) that student/ teacher ratio, availability of good text books are among the significant factors which influence students progression hence grade promotion rates.

The findings of the current study further resolve the conflict between the findings of the study by Macgowen (2007) and study by Souck et al. (2017) about whether there is significant relationship between school facility conditions and internal efficiency. The resolve has been achieved by diversifying sources of information as well as method of collecting them focusing mainly on achieved key performance indicators under curriculum and instruction without mixing the indicators of physical infrastructure. The current study findings equally resonate with the finding of the study by Charles (2009) that inadequate provision of teaching and learning resources pose a great hindrance in attaining quality objective of education, by establishing that availing text books, revision books, improved pedagogy, increased science practicals and increased teacher/student contact time greatly influence grade promotion rate and retention rate hence internal efficiency in public secondary schools.

The results from both quantitative and qualitative findings corroborate that plans of schools in the study locale are comprehensive by not only focusing on material resources alone such as buses and buildings but also teaching and learning. This disconfirms the findings of other researchers who argue that some schools' plans are not comprehensive since they focus on material resources for the schools such as buses and buildings, ignoring teaching and learning (Reeves, 2008; Rumelt, 2011). The results from both quantitative and qualitative findings further established that schools in the study locale have the goal of developing an all - round student and have effective programmes to monitor and evaluate growth in teacher performance and professional development. This finding exonerates the schools in the study locale from the list of schools without comprehensive plans according to Wanjala, et al. (2014) which lay great emphasis on the result of paper and pencil tests, thereby ignoring the goal of developing an all - round student; and in addition the plans display ineffective programmes to establish, monitor and evaluate growth in teacher performance and professional development, when this area is crucial in improving classroom practice and teaching methodology, which finally improves student achievement (Balogu, et. al. 2008; Wanjala, et. al. 2014).

\section{CONCLUSIONS AND RECOMMENDATIONS}

The main concern of the study presented in this paper was to convey the issue of achieved key performance indicators in curriculum and instruction and the effect it has on internal efficiency in public secondary schools in 
the study locale. Based on the research findings and discussion of the findings in relation to the art of literature, it is concluded that achieved key performance indicators has moderate influence on internal efficiency, particularly on grade promotion rate in public secondary schools in Kisumu and Uasin Gishu Counties, Kenya. On the basis of the findings, summary and conclusions, the following recommendations are made. The Government of Kenya through the Ministry of Education and together with the stakeholders in various secondary schools should undertaking the following:

One, in order to improve the pedagogy, schools should involve stakeholders in identifying training needs of the teachers in tandem with subjects prioritized for improvement and then organize in-service education training (INSET) for the affected teachers instead of waiting for SMASSE and other joint sub-county or county trainings organized by the ministry.

Two, the government (MoE) should increase and make available grants for revision books/materials to schools so that each school can avail these materials based on their specific needs. However, supply of text books by the government directly to schools to be continued.

\section{Declaration of Competing Interests}

We wish to declare that this paper has been developed purely from my postgraduate academic research thesis that was self-sponsored in its entirety. We also wish to declare that no personal business interests or affiliations to any school, company or organization that may claim party or will be affected/beneficial from the research findings of this paper.

\section{References}

Adepoju, T. L., \& Oluchukwu, E. E. (2011). A study of secondary schools students' academic performance at the Senior School Certificate Examinations and Implications for Educational Planning and Policy in Nigeria. African Journals Online. Issue Vol 5 No. 6 ISSN: 1994-9057.

Baloghu, N., Karadog,E., Karaman, H.(2008). The strategic planning attitude scale: A study of explanatory and confirmatory factor analysis. Educational Sciences: Theory and Practice 8(2): 429 - 437.

Charles, L. (2009). Internal efficiency measures in promotion of access and completion rates in public secondary school of Bungoma South District. Retrieved from http:/erepository.uanbi.ace.8080/xmului/handle/123456789/20631discussion paper No. 55.

Chemwei, B., Leboo, C., \& Koech, S. J. (2014). Factors that Impede the implementation of strategic plans in secondary schools in Baringo District, Kenya. International Journal of Humanities and Social Science 4(5).

Chukwumah. F.O., \& Ezeugbor, C.O. (2015). Problems of implementation of strategic plans for secondary schools' improvement in Anambra State. Academic Journals Vol (10)(10) pp.1384-1389.

Creswell, J. W. (2014). Research design: Qualitative, quantitative and mixed methods approaches (4th Ed.). Thousand Oaks, CA: Sage.

Gupta, M. (2015). How to use key performance indicators for strategy implementation. http://www.strategicthinking.eu/resource-and-reference-on-key-performance- indicators.

IIEP. (2010). Strategic planning: concept and rationale. Education Centre working papers. Working paper 1. UNESCO.

Kaufman, R. \& Herman, I. (2018). Strategic planning for a better society. Retrieved from www.ascd.org/ /e/ 199104-Kaufmanpdf.

Khan, J. W. M \& Khalique, M. (2014). A holistic review of empirical studies of strategic planning and future research avenues. International Journal of Academic Research in Economics and Management Science Vol. 3, No. 6 ISSN:2226-362.

Macgowen, R.S. (2007). The impact of school facilities on students, achievement, attendance, behavior, completion rate and teacher turnout rate at selected Texas High schools. University of Houston.

Orodho, A.J. (2017). Techniques of writing research proposals and reports in education and social sciences: An illustrative guide to scholarly excellence. Kanezja publishers, Nairobi, Kenya. ISSBN: 978-9966-7350-0-3.

Orodho, A.J., Ampofo, S.Y., Bizimana, B., \& Ndayambaje, I.(2016). Quantitative Data Management: A step by step guide to data analysis using Statistical Package for Social Sciences (SPSS) Computer software. Kanezja publishers, Nairobi, Kenya. ISBN: 978-9966-7350-3-8.

Orodho, J.A., Nzabalirwa, W., Odundo, P., Waweru, P ., \& Ndayambaje ,I. (2016). Quantitative and Qualitative Research Methods: A step by step guide to scholarly excellence. Kanezja publishers, Nairobi, Nairobi. ISBN: 978-9966-7350-3-8.

Otieno, O. T, (2015). School-based determinants of promotion rates among public primary schools in Suba SubCounty, Kenya. Unpublished Med Thesis Kenyatta University.

Rajput, R. (2019). The future entrenching STEM education in Africa. Star Blogs.

Reeves, D. (2007). Making strategic planning work. Educational Leadership, 65(4): 86. Retrieved July 8, 2009 , from Middle Search Phis database. 
Reeves, D. D. (2008). Leading to change / making strategic planning work Educational Leadership Journal 65(4): $86-97$.

Republic of South Africa. (2013). The internal efficiency of the school system. Department of Basic Education.

Ricardo, S., Akyeampong, K., Westbrook, J., \& Hunt, F. (2010). School dropout: Patterns, causes, changes and policies. Paper Commissioned for thee EFA Global Monitoring Report 2011, the hidden Crisis: Armed conflict and Education. UNESCO.umwelt, R.P.(2011). Good Strategy and Bad Strategy: The Difference and why it matters. New York: Crown Business.

Sang, A. K. A. Koros, P.K.A. \& Bosire J.N. (2013). An analysis on dropout levels of public secondary schools in Kericho District in relation to selected school characteristics. International Education Studies 6(7) Canadian Center of Science and Education.

Souck, E. N., \& Nji, G. (2017). The effects of School facilities on internal efficiency: The case of selected bilingual secondary schools in Yaunde Centre. World Journal of Research and Review (WJRR) ISSSN: 2454-3956, Vol 4 Iss 4, April, 2017 41-48.

Wanjala, N.C. \& Rarieya, F.A.J. (2014). Strategic planning in schools in Kenya: Possibilities and Challenges. ISEA. Volume 42, Number 1, 2014 /17. 